*ak RMIS View/Frint Document Cover Sheet tow

This document was retrieved from the Documentation and Records Manaqement (DRM) ISEARCH System. It is intended for Information only and may not be the most recent or updated version. Contact a Document Service Center (see Hanford Info for locations) if you need additional retrieval information.

Accession \#: D195061610

Document \#: SD-TD-TI-003

Title/Desc:

SUMMARY REPORT OF FY 1995 RAMAN SPECTROSCOPY TECHNOLOGY DEVELOPMENT

Pages: 83 


\section{To: (Receiving Organization) \\ Distribution}

5. Proj./Pros./Dept./Div.:
$8 A 800$

8. Originator Ramarks:

Release of WHC-SD-TD-TI-003, Rev. 0

3. Fron: (originating organization)

Remote Systems and Sensor Applications

6. Cog. Engr.:

J. G. Douglas
4. Related EDT No.:

NA

7. Purchese Order No.:

NA

9. Equip./Component No.:

NA

10. Syaten/Bldg./Facility:

NA

11. Receiver Renarks:

12. Major Asan. Dwg. Mo.:

NA

13. Permit/Permit Application No.: NA

14. Reculired Response Date:

NA

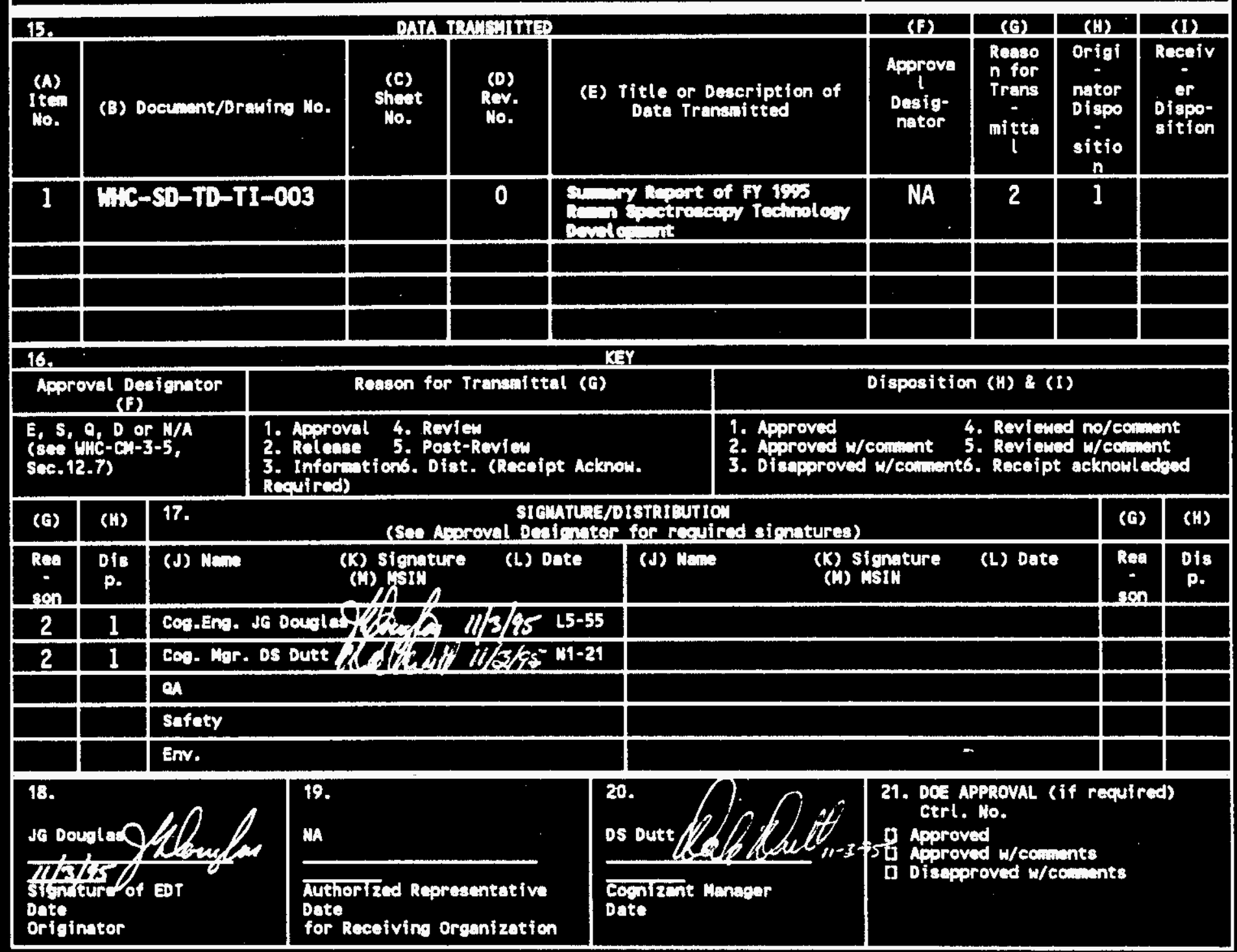

$80-7400-172-2(04 / 94)$ GEF097 
Blane 


\section{RELEASE AUTHORIZATION}

Document Number: WHC-SD-TD-TI-003, Rev. 0

Suminary Report of FY 1995 Raman Spectroscopy

Technology Development

Reloase Date: $\quad 11 / 07 / 95$

This document was reviewed following the procedures described in WHC-CM-3-4 and is:

APPROVED FOR PUBLIC RELEASE

WHC Information Release Adminiatration Specialist:

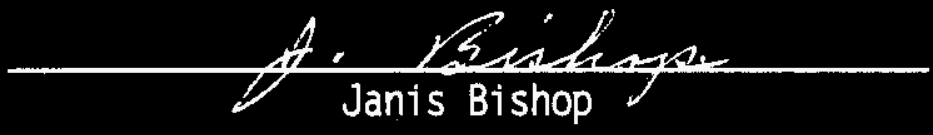

$11 / 07 / 95$

TRADEMAR DISCLAIMER. Reference herein to any specific commercial product. process, or service by trade name, trademark. manufacturer, or otherwise, does not necessarily constitute or imply its endorsement, recommendation, or favoring by the United States Government or any agency thereof or its contractors or subcontractors.

This report has been reproduced from the best available copy. Available in paper copy. Printed in the United States of Anerica. To obtain copies of this report, contact:

Westinghouse Hanford Company - Document Control Services

P.0. Box 1970. Mailstop H6-08, Richland, WA 99352

Telephone: (509) 372-2420; Fax: (509) 376-4989 
Blank 


\begin{tabular}{|c|c|c|}
\hline $\begin{array}{l}\text { 2. ritle } \\
\text { Summary Report of FY } 1995 \text { Raman Spectroscopy } \\
\text { Technology Development }\end{array}$ & $\begin{array}{l}\text { 3. Nunber } \\
\text { HHC-SD-TD-TI-003 }\end{array}$ & $\begin{array}{c}\text { 4. Rev No. } \\
0\end{array}$ \\
\hline $\begin{array}{l}\text { 5. Koy Worda } \\
\text { Raman, spectroscopy, fiber optics, remote, } \\
\text { sensing, tank, high-level, radioactive, waste, } \\
\text { characterization, simulant, technology } \\
\text { development, cone penetrometer, Light-Duty Utility } \\
\text { Arm, LDUA, hot cell }\end{array}$ & $\begin{array}{l}\text { 6. Author } \\
\text { Nene: JG Douglas } \\
\text { Orgenization/charge code }\end{array}$ & $84800 / A$ \\
\hline
\end{tabular}

\section{Abstract}

The U.S. Department of Energy is sponsoring the development of remote, fiber-optic Raman spectroscopy for the rapid chemical characterization of Hanford-Site highlevel radioactive tank waste. The deployment targets for this technology are analytical hot cells and, via the Light-Duty Utility Arm and cone penetrometer, the waste tanks themselves. Perceived benefits of fiber-optic Raman spectroscopy are (1) rapid generation of tank-waste safety-related data, (2) reduced personnel exposure to highly radioactive waste, (3) reduced tank-waste sampling and analys is costs, and (4) reduced radioactive analytical waste.

This document presents the results from the investigation of two dispersive, transmission-grating Raman systems and four fiber-optic Raman probe designs with non-radioactive tank waste simulants. One Raman system used a $532-\mathrm{nm}, 400 \mathrm{~mW}$, solid-state laser; the other used a 785-nm, $500 \mathrm{~mW}$, solid-state diode laser. We found (1) the transmission-grating systems had better wavelength stability than previousiy tried Czerny-Turner-based systems and (2) the 785-nm system's specie detection limits in the spectral fingerprint region were at least as good as those for the 532-nm system. Based on these results, and the fact that some tank wastes luminesce with 514.5-nm excitation, we selected the 785-nm system for hot-ce11 use.

Of the four probes tested, three had a "six-around-one" fiber probe design; the fourth probe was a one-fiber-in-one-fiber-out, diffuse-reflectance design.

Comparison of the four probes' signal-to-noise ratios, transmission/collection efficiencies, and probe-silica Raman backgrounds showed that the best probe for use with Hanford-Site tank waste should (1) be filtered as close to the probe tip as possible to reduce the probe-silica Raman background and (2) have multiple collection fibers. The responses of all the probes tested showed a strong dependence on probe-sample distance, and the presence of a probe window appeared to increase the probe's silica Raman background.

8.

returs stap

OFFICIAL PELEAE:

DY Vita

DATE

NOV 071995

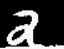


Blank 


\title{
Summary Report of FY 1995 Raman Spectroscopy Technology Development
}

\author{
J. C. Douglas \\ F. R. Reich \\ Weatinghouse Hanford Company
}

Thb decument ls avallablo from the arthore in WordPerisctis $8 . x$ format. 
WHC-SB-TD-TL-003, Rov. 0

This page intentionally blank 


\section{TABLE OF CONTENTS}

LIST OF FIGURES $\ldots \ldots \ldots \ldots \ldots \ldots \ldots \ldots \ldots \ldots \ldots \ldots \ldots \ldots \ldots \ldots \ldots \ldots \ldots \ldots$ iv

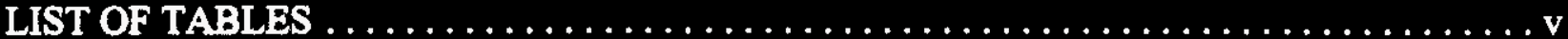

LIST OF TRADEMARKS $\ldots \ldots \ldots \ldots \ldots \ldots \ldots \ldots \ldots \ldots \ldots \ldots \ldots \ldots \ldots \ldots$ vi

LIST OF ACRONYMS AND ABBREVIATIONS $\ldots \ldots \ldots \ldots \ldots \ldots \ldots \ldots$ vii

EXECUTTVE SUMMARY $\ldots \ldots \ldots \ldots \ldots \ldots \ldots \ldots \ldots \ldots \ldots \ldots \ldots \ldots \ldots \ldots \ldots$ ix

1.0 INTRODUCTION $\ldots \ldots \ldots \ldots \ldots \ldots \ldots \ldots \ldots \ldots \ldots \ldots \ldots \ldots \ldots \ldots \ldots \ldots, 1-1$

1.1 Background $\ldots \ldots \ldots \ldots \ldots \ldots \ldots \ldots \ldots \ldots \ldots \ldots \ldots \ldots \ldots \ldots, \ldots \ldots \ldots, 1$

1.2 Previous Work $\ldots \ldots \ldots \ldots \ldots \ldots \ldots \ldots \ldots \ldots \ldots \ldots \ldots \ldots \ldots \ldots \ldots, 1-3$

2.0 EXPERIMENTAL $\ldots \ldots \ldots \ldots \ldots \ldots \ldots \ldots \ldots \ldots \ldots \ldots \ldots \ldots \ldots \ldots \ldots \ldots, 2-1$

2.1 Fiber-Optic Raman Probes $\ldots \ldots \ldots \ldots \ldots \ldots \ldots \ldots \ldots \ldots \ldots \ldots \ldots, 2-1$

2.2 Raman Spectroscopy Systems $\ldots \ldots \ldots \ldots \ldots \ldots \ldots \ldots \ldots \ldots \ldots \ldots, 2-7$

2.3 Materials and Sample Preparation $\ldots \ldots \ldots \ldots \ldots \ldots \ldots \ldots \ldots \ldots \ldots \ldots, \ldots \ldots \ldots$

2.4 Light Sources $\ldots \ldots \ldots \ldots \ldots \ldots \ldots \ldots \ldots \ldots \ldots \ldots \ldots \ldots \ldots, 2-9$

3.0 RESULTS AND DISCUSSION $\ldots \ldots \ldots \ldots \ldots \ldots \ldots \ldots \ldots \ldots \ldots \ldots \ldots, \ldots \ldots \ldots$

$3.1532-\mathrm{nm}$ vs. 785-nm Excitation ............................ 3-1

3.2 Comparison of Fiber-Optic Raman Probes $\ldots \ldots \ldots \ldots \ldots \ldots \ldots \ldots \ldots .4 .4 \ldots \ldots \ldots$

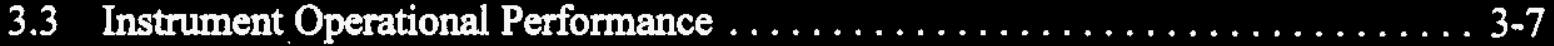

4.0 CONCLUSIONS AND FUTURE WORK $\ldots \ldots \ldots \ldots \ldots \ldots \ldots \ldots \ldots \ldots \ldots, \ldots \ldots \ldots$

4.1 Conclusions $\ldots \ldots \ldots \ldots \ldots \ldots \ldots \ldots \ldots \ldots \ldots \ldots \ldots \ldots \ldots \ldots, \ldots \ldots \ldots, 1$

4.2 Future Work $\ldots \ldots \ldots \ldots \ldots \ldots \ldots \ldots \ldots \ldots \ldots \ldots, \ldots \ldots \ldots, 2$

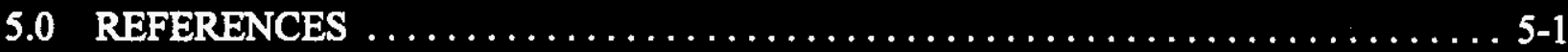

APPENDIX A: TANK WASTE SIMULANT CHEMICAL COMPOSITIONS . . . . . . . A-1

APPENDIX B: NEON CALIBRATION AND SODIUM-VAPOR LAMP SPECTRA .... B-1

APPENDIX C: RAMAN COMPARISON SPECTRA AT 532 NM AND 785 NM . . . . . C - 1 


\section{WHC-SD-TD-TH-003, Rov. 0}

\section{LLIST OF FICURES}

Figure 2.1. Probe (1): WSRC Prototype Raman Probe-Head Design for In Situ Tank

Deployment with the Light-Duty Utility Arm. . . . . . . . . . . . . . . . . . 2-2

Figure 2.2. Probe (1): Optical Design of the WSRC Prototype Raman Probe Head. . . . . . . 2 2-3

Figure 2.3. Probe (2): LLNL Flat-Face, 6-Around-1, Fiber-Optic Probe. . . . . . . . . . 2-4

Figure 2.4. Probe (3): LLNL Flat-Face, 6-Around-1 Fiber-Optic Probe with In-Line Optical

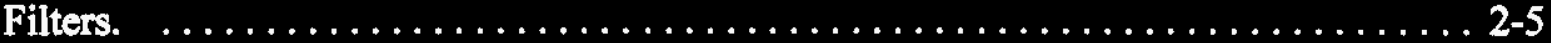

Figure 2.5. Probe (4): Diffuse-Reflectance Probe with In-Line Optical Filters. . . . . . . . . 2-6

Figure 2.6. Optical Layout of Kaiser Optical Systems, Inc., HoloSpec f/1.8 Transmission

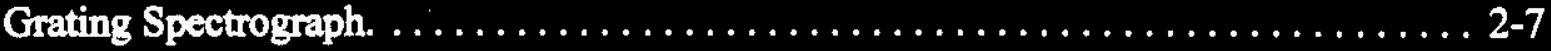

Figure 3.1. Probe Response as a Function of Probe/Target Separation Distance for Three Fiber-

Optic Raman Probes. $\ldots \ldots \ldots \ldots \ldots \ldots \ldots \ldots \ldots \ldots \ldots \ldots \ldots . \ldots . \ldots .4$

Figure 3.2. White-Light Spectra for 532-nm and 785-nm Gratings with LN/CCD-1024TKB

CCD Detector. . . . . . . . . . . . . . . . . . . . . . . . . . . . . .

Figure B.1. Neon Calibration Lines for Kaiser 532-nm Spectrograph (167- $\mu m$ slit). . . . . . . B-2

Figure B.2. Neon Calibration Lines for Kaiser 785-nm Spectrograph (167- $\mu \mathrm{m}$ slit). . . . . . . B-3

Figure B.3. Spectrum of High-Pressure Sodium Vapor Lamp: 800 - $920 \mathrm{~nm} . \ldots . \ldots$. . . . . B-4

Figure B.4. Spectrum of High-Pressure Sodium Vapor Lamp: 910 - $1040 \mathrm{~nm} . . . \ldots$. . . . . B-4

Figure C.1. Sodium Nitrate Raman Spectra Using 532-nm and 785-nm Excitation. . . . . . . C-2

Figure C.2. Acetonitrile Raman Spectra Using 532-nm and 785-nm Excitation. . . . . . . . . C-2

Figure C.3. Cyclohexane Raman Spectra Using 532-nm and 785-nm Excitation. . . . . . . . C. C

Figure C.4. Sodium Nickel Ferrocyanide Raman Spectra Using 532-nm and 785-nm

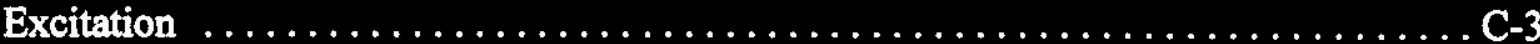

Figure C.5. BY-104 Simulant Raman Spectra Using 532-nm and 785-nm Excitation. . . . . . C-4

Figure C.6. In-Farm 2 Simulant Raman Spectra Using 532-nm and 785-nm Excitation. . . . . C-4

Figure C.7. SY-101 Simulant Raman Spectra Using 532-nm and 785-nm Excitation. . . . . . C-5

Figure C.8. T-Plant (Bottom Fraction) Simulant Raman Spectra Using 532-nm and 785-nm

Excitation. .................................... C-5

Figure C.9. T-Plant (Top Fraction) Simulant Raman Spectra Using 532-nm and 785-nm

Excitation. ...................................6 


\section{LIST OF TABLES}

Table 3.1. Comparison of Wavelength and Wavenumber Coverage and Resolution for the 532-nm and 785 -nm Systems. . . . . . . . . . . .

Table 3.2. Comparison of Signal-to-Noise Ratios for the 532-nm and 785-nm Systems. . . . 3-2

Table 3.3. Comparison of Specie Detection Limits for 532-nm and 785-nm Systems. . . . . . 3-3

Table 3.4. Comperison of Probe Characteristics for Fiber-Optic Raman Probes. . . . . . . . 3-6

Table 3.5. Comparison of Signal-to-Noise Ratios for 167- $\mu \mathrm{m}$ and $250-\mu \mathrm{m}$ Slit Widths. . . . 3-9

Table 3.6. Compacieon of Signal-to-Noise Ratios for the LN/CCD-1024TKB and

TEA/CCD-1152EM/1 CCD Detectors. ....................... 3-10

Table A.1. BY-104 Salt-Cake Simulant Composition. . . . . . . . . . . . . . . A-2

Table A.2. In-Farm 2 "Mixed" Simulant Composition. . . . . . . . . . . . . . . A-2

Table A.3. SY-101 Simulant Composition. ......................... A-3

Table A.4. T-Plant "Top" Simulant Composition. ..................... A-4

Table A.5. T-Plant "Bottom" Simulant Composition. ................... A-5

Table C.1. Experimental Conditions for Figures C.1 - C.9. ............... C-1 


\section{LIST OF TRADEMARKS}

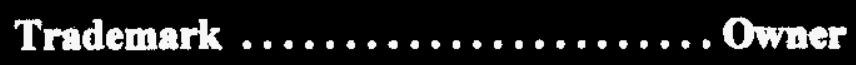

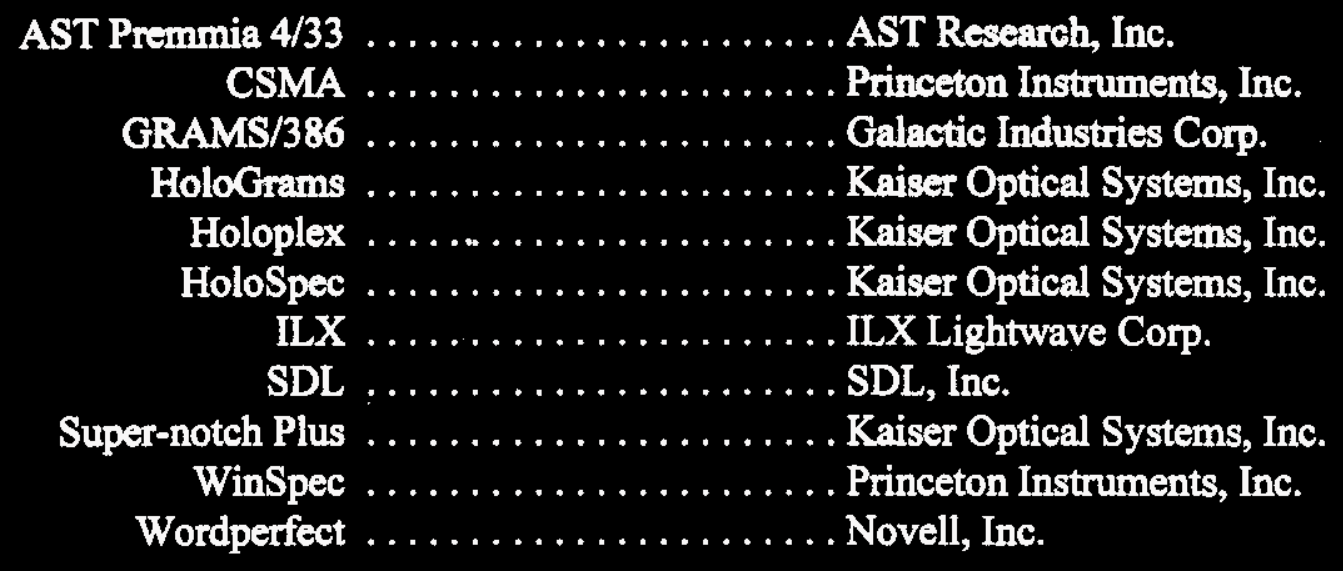




\section{LIST OF ACRONYMS AND ABBREVIATIONS}

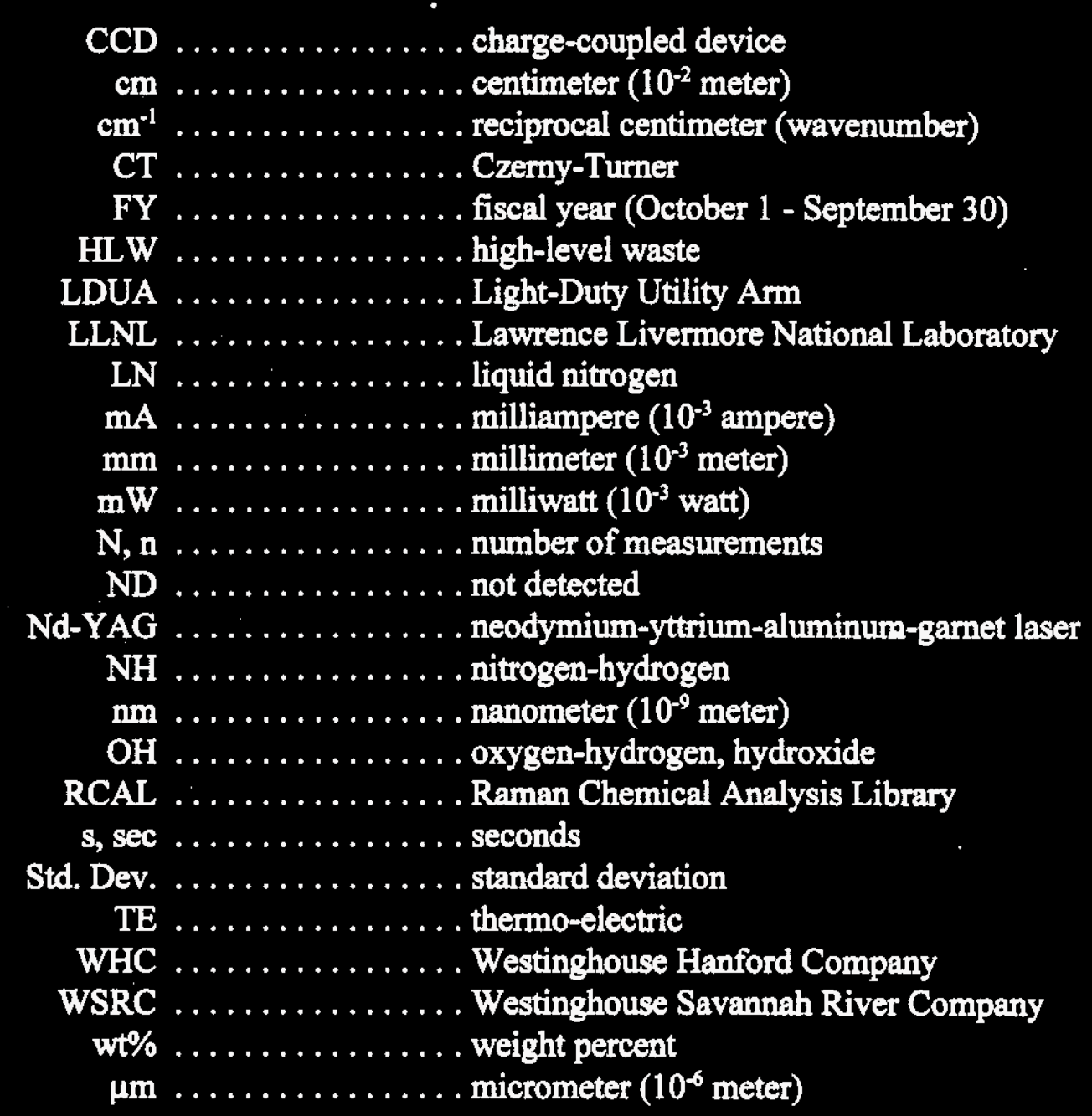


WHT-SD-TD-TI-003, Rev. 0

This page intentionally blank 


\section{EXZCUTME SUMMARY}

This report documents the optimization and testing of two Raman spectroscopy systems and four fiber-optic Raman probes in a non-radioactive environment. We are developing Raman spectroscopy systems for the remote characterization of Hanford-Site high-level tank waste. Ultimate deployment of these systems will be both in the hot cell and, via the Light-Duty Utility Arm (LDUA) and cone penetrometer, in the waste tanks themselves. The drivers for this development effort are (1) the need to rapidly obtain safety-related information about the organic and ferrocyanide contents of tank waste and (2) the desire to reduce taink waste characterization costs through rapid chemical screening of tahk waste. The Department of Energy's Offices of Technology Development and Tank Waste Remediation Systems are jointly sponsoring this development effort.

The Raman systems examined in this report were two Kaiser Optical Systems, Inc., speetrographs - one operating at $532 \mathrm{~nm}$ and the other at $785 \mathrm{~nm}$. An Adlas, Inc., doubled neodymium-yttrium-aluminum-garnet (Nd-YAG) laser supplied the 532-nm excitation, while an SDL, Inc., tunable diode laser supplied the 785-nm excitation.

The two Kaiser systems have no moving parts and use transmission gratings instead of the reflective optics and wavelength scanning mechanisms of previously examined Czerny-Tumerbased Raman spectrographs. We found that the Kaiser Raman systems exhibited improved wavelength stability, better through-put, and a more compact package than our Czerny-Tumerbased Raman systems. These advantages are gained with no loss in resolution, wavelength coverage, or detection limit capability.

Comparisons of the two Kaiser systems led to the choice of the 785-nm system for near-term deployment in the hot cell. The two systems were compared on:

(1) Signal-to-noise ratios of sodium nitrate and detection limits for various Raman-active components in non-radioactive tank waste simulants. The two systems have similar signalto-noise ratio characteristics for pure sodium nitrate. The 785-nm system gives somewhat better detection limits for the oxyanion components in the tank waste simulants while the 532-nm system yields better detection limits for ferrocyanide materials.

(2) Spectral coverage and resolution. The 532-nm system provides spectral coverage up to about $4000 \mathrm{~cm}^{-1}$ while the $785-\mathrm{nm}$ system gives covers through about $3100 \mathrm{~cm}^{-1}$; this implies the 532-nm system can cover the NH- and OH-stretch spectral regions while the 785-nm system cannot. Wavenumber resolution is about equivalent for the two systems.

(3) Likelihood of the excitation radiation to generate interfering sample luminescence in real tank waste. The likelihood of exciting Raman-interfering sample luminescence increases at shorter wavelengths. We have observed sample luminescence in some real tank waste using 
514.5-nm excitation; this interfering luminescence is likely to be greatly reduced with 785nm excitation. Since sample luminescence, when present, will likely determine the detection limits of components in tank waste, we chose the 785-nm Raman system as the optimal choice for hot-cell deployment.

We measured and compared several optical characteristics of four fiber-optic probes to determine the optimal characteristics of a Raman probe to be used for tank waste measurements. The four probes were: (1) a Weatinghouse Savannah River Company (WSRC) LDUA prototype probe with six-around-one fiber arrangement, conical tip, sapphire window, and optical filters; (2) a Lawrence Livermore National Laboratories (LLNL) -supplied probe with six-around-one fiber arrangement, flat-faced probe; no window or filters; (3) an LLNL-supplied probe with sixaround-one fiber arrangement, flat-faced, with filters; no window; (4) a Polytec PI, Inc., one-inone-out probe with filters; no window. The probe characteristics we measured for each probe were: (1) probe silica Raman rejection, (2) "efficiency", (3) overall signal-to-noise ratio, (4) optimal probe-sample separation distance, and (5) probe excitation spot size.

Overall, the WSRC LDUA probe had a good combination of signal-to-noise ratio, efficiency, and probe silica Raman rejection characteristics. However, the Polytec PI probe delivered better signal-to-noise ratio and probe silica Raman rejection values. The responses of all the probes exhibit a strong dependency on the probe-sample lift-off distance. The results of these probe tests indicate that an ideal Raman probe design for Hanford-Site tank waste will have these features:

(1) optical filters placed as close to the probe tip as possible to minimize the probe's silica response and thus improve signal-to-noise ratio,

(2) multiple return fibers to yield better collection efficiencies,

(3) no probe window to degrade the silica rejection afforded by the optical filtering.

The probe should also have a spot size large enough to excite a representative area of the sample (probably $>1 \mathrm{~mm}$ ) and to minimize photo-induced damage to the sample. Finally, the probe response either should exhibit little dependency on the probe-sample distance, or the probe must be fitted with a mechanism to reproducibly set the probe-sample distance.

We have some additional work to be perform before hot-cell deployment of the 785-nm system in FY 1996. This work includes (1) testing a Kaiser Optical Systems, Inc., 785-nm Raman probe for possible deployment in the hot cell, (2) finalizing and packaging the 785-nm system for hotcell deployment and (3) selecting the software for instrument control and data reduction. 


\subsection{INTRODUCTION}

\subsection{Background}

This report summarizes the FY 1995 Raman spectroscopy technology development and testing completed with non-radioactive materials in a non-radioactive environment. The Department of Energy's (DOE) offices of Technology Development (EM-50) and Tank Waste Remediation Systems (EM-30) are jointly sponsoring development of Raman technology to obtain chemical information from Hanford Site high-level radioactive waste (HLW) both in the hot cell and in Hanford Site waste tanks. The prinsipd drivers for this development effort are:

(1) to obtain safety-related information about the ferrocyanide and organic content of tank waste, and

(2) to reduce tank waste characterization costs through rapid chemical screening of tank waste.

We performed the Raman spectroscopy work reported in this document using reference materials and non-radioactive, simulated tank wastes in a non-radioactive test facility at the Hanford Site's 305 Building. Non-radioactive testing and development work is part of the development path being followed in the application of Raman spectroscopy to Hanford-Site HLW materials. The EM-50 Office of Technology Development is providing support for the development and optimization of the basic Raman system and system components. The EM-30 Tank Waste Safety and Tank Waste Remediation Systems programs at the Hanford Site are supporting the application of this technology for hot-cell testing and deployment.

Raman spectroscopy uses a laser and a spectrograph to produce vibrational spectra of Ramanactive molecules in a sample; the sample may be a gas, liquid, or solid. We can obtain both qualitative and quantitative information from a Raman spectrum. Qualitatively, each molecular specie in the sample generates a different spectral pattern unique to that specie; we can use these patterns to identify the species in the sample. Quantitatively, the intensity of the bands in the spectrum are proportional to the concentration of the species in the sample. Silica optical fibers provide a convenient way to route the laser's emission to a remote sample and return the Ramanscattered radiation to the spectrograph. In simple matrices, remote, fiber-optic Raman spectroscopy can rapidly determine both the identities and amounts of molecular species of interest in Hanford Site HLW (Mann and Vickers 1994).

The need to rapidly and economically identify and quantitate the molecular species in radioactive tank wastes is the principal driver for the development and deployment of remote, fiber-optic Raman spectroscopy. A number of tank waste data quality objectives require characterization data for (1) safe tank farm operations and (2) the development of the technologies required to stabilize and process radioactive waste materials (Brown et al. 1995). At present, safe tank farm operations are dominating the need for tank waste characterization data. The existence of 
potential organic and ferrocyanide fuels mixed with oxidizers in tank waste raises the possibility of unsafe conditions in the tanks (Postma et al. 1994). In the future, we will also need waste characterization data to support technologies for retrieving, processing, and stabilizing radioactive wastes.

To support these characterization data needs, a remote, fiber-optic, Raman spectroscopy probe may provide both qualitative and quantitative data from radioactive tank waste both in the hot cell and in the waste tanks themselves. Deploying remote Raman spectroscopy in a hot cell serves two separate purposes:

(1) we must verify that remote Raman technology can provide useful information from actual tank waste prior to attempting the expensive deployment of the technology in the tanks themselves and

(2) we have the added benefit of using the Raman probe as a hot-cell screening tool to allow the rapid collection of characterization data from hot-cell-extruded core segments, the reduction or elimination of sample preparation steps, and the subsequent reduction in the number of traditional chemical analyses.

In the current tank waste characterization process, waste core segments are extracted from a tank and extruded in a hot cell where sub-samples are selected for detailed chemical analyses. The subsequent analytical tests performed on these samples require significant sample preparation and pretreatment. These tests are labor intensive, time consuming, and result in the generation of secondary waste. Use of a hot-cell Raman probe to reduce or eliminate some of these tests will allow savings in cost, time, and personnel exposure. A hot-cell Raman probe may also quickly provide species profiles along the axis of the core sample that are not possible with current methods. These species profiles may help reduce the number of sub-samples required for subsequent laboratory chemical analysis, thus reducing the total analysis cost for a core segment.

We are also pursuing in-tank deployment of remote, fiber-optic Raman probes with the Light Duty Utility Arm (LDUA) and Cone Penetrometer. An in-tank Raman probe could support both qualitative and quantitative analysis and thus reduce the need for waste extraction from a tank and subsequent hot-cell analysis. The use of remote, fiber-optic Raman spectroscopy as a characterization tool for hot-cell and in-tank use offers significant reductions in time, cost, and secondary waste generation; these potential benefits provide the principal motivation for the development of remote, fiber-optic Raman spectroscopy. 


\subsection{Provious Work}

In previous work to support the application of Raman spectroscopy to Hanford-Site tank waste (Lopez et al. 1995), we tested several Raman probe designs using a Czerny-Turner-based Raman spectrograph and either 514.5- or 532-nm laser excitation. Those tests examined features of Raman probes that are desirable for use with tank waste. Desirable probe features include (1) optical filters in the probe to reduce the probe's silica response and improved the signal-to-noise ratio in the fingerprint/oxyanion spectral region (but at the expense of the probe's optical throughput) and (2) multiple return fibers to improve the probe's efficiency in delivering light to the spectrograph. Section 3.2 of this document presents results that confirm those previous observations and further our understanding of what features a fiber-optic Raman probe needs for use with tank waste samples.

Lopez et al. 1995 also indicated some deficiencies with the Czerny-Turner-based Raman spectrograph and the 514.5- and 532-nm excitation wavelengths. These deficiencies included (1) wavelength drift in the Czemy-Tumer spectrograph during operation (probably due to ambient temperature variations), (2) generation of a large ambient heat load by the air-cooled argon-ion laser (514.5-nm source), and (3) the discovery, through diffuse-reflectance spectra, that the tank waste simulants are more likely to absorb the 514.5- and 532-nm wavelengths (and the Raman scattering associated with those wavelengths) than near-infrared wavelengths. Furthermore, some actual tank waste samples exhibit luminescence when excited with 514.5-nm light.

This report presents the results of our investigations to address these deficiencies: We explored the use of two Raman systems based on transmissive optics (instead of the reflective optics of the Czerny-Tumer design); one Raman system was optimized for 532-nm operation, the other for 785-nm operation. The 532- and 785- $\mathrm{nm}$ lasers used in the current investigation are solid-state lasers with almost none of the excess heat generation of the argon-ion laser. We chose to examine the use of 785-nm excitation to determine how well the longer wavelength excitation would work with tank waste simulants; 785-nm excitation should generate much less luminescence in actual tank samples than green-light excitation. The investigation of nearinfrared excitation also follows the recommendation of the Raman Spectroscopy Peer Review Report (Winkelman and Eberlein 1994). 
WHC-SO-TD-TI-003, Rev. 0

This page intentionally blank 


\subsection{EXPERIMENTAL}

This section outlines the equipment, material, and procedures used to perform equipment tests and measurements. Section 2.1 discusses the four probes examined in this study, Section 2.2 describes the 532-nm and 785-nm Raman systems, Section 2.3 outlines materials and sample preparation, and Section 2.4 describes the non-laser light sources used in this study.

\subsection{Fiber-Optlc Raman Probes}

We examined four probes in these studies; see Figures 2.1 - 2.5 for diagrams of each probe:

(1) Westinghouse Savannah River Company (WSRC) Light-Duty Utility Arm (LDUA) probe: six-around-one, 400- $\mu \mathrm{m}$ diameter, stipped-index silica fibers, conical tip, with sapphire window and optical filters (Figures 2.1, 2.2),

(2) Lawrence Livermore National Laboratories (LLNL) -supplied probe: six-around-one, 400$\mu \mathrm{m}$ diameter, stepped-index silica fibers, flat-faced; no window or filters (Figure 2.3),

(3) LLNL-supplied probe: six-around-one, 200- $\mu \mathrm{m}$ diameter, stepped-index silica fibers, flatfaced with filters; no window (Figure 2.4),

(4) Polytec PI, Inc., one-in-one-out probe with filters; no window (Figure 2.5).

Probe (1) is a prototype probe for the LDUA. This probe differs from others previously examined in that it has in-line filters much closer to the probe tip (see Figure 2.1) and has a conical tip that provides more complete overlap between the excitation region of the central fiber and the viewing regions of the surrounding fibers (see Figure 2.2). Probe (3) is similar in design to probe (2) except that probe (3) has 200- $\mu \mathrm{m}$ fibers and in-line filters. The desire to test a 200$\mu \mathrm{m}$ fiber probe was to determine if matching fiber diameter more closely to the spectrograph's slit width would improve the Ramen system's overall throughput. Lopez et al. 1995, contains more complete descriptions of probes (2) and (4).

CVI Laser Corp. (Albuquerque, NM) provided the optical filters used in the filtered probes. The filters are nominally 3-mm in diameter and 0.5-mm thick to allow insertion in standard SMA-905 connectors. The laser band-pass filters are dielectric filters with a peak transmission of $c a .50 \%$ at $532 \pm 0.6 \mathrm{~nm}$ or $785 \pm 0.6 \mathrm{~nm}$ and a half-height peak width of $c a .6 \mathrm{~nm}$. The long-pass filters have a transmittance of about $12 \%$ at the laser wavelength and a maximum transmittance of about $70 \%$ at wavelengths about $80 \mathrm{~nm}$ longer than the excitation wavelength. 
WHC.BB-TD-TI-003, Rov. 0

Figure 2.1. Probe (1): WSRC Prototype Raman Probe-Head Dedign for In Situ Tank Deployment with the Light-Duty Utility Arm.

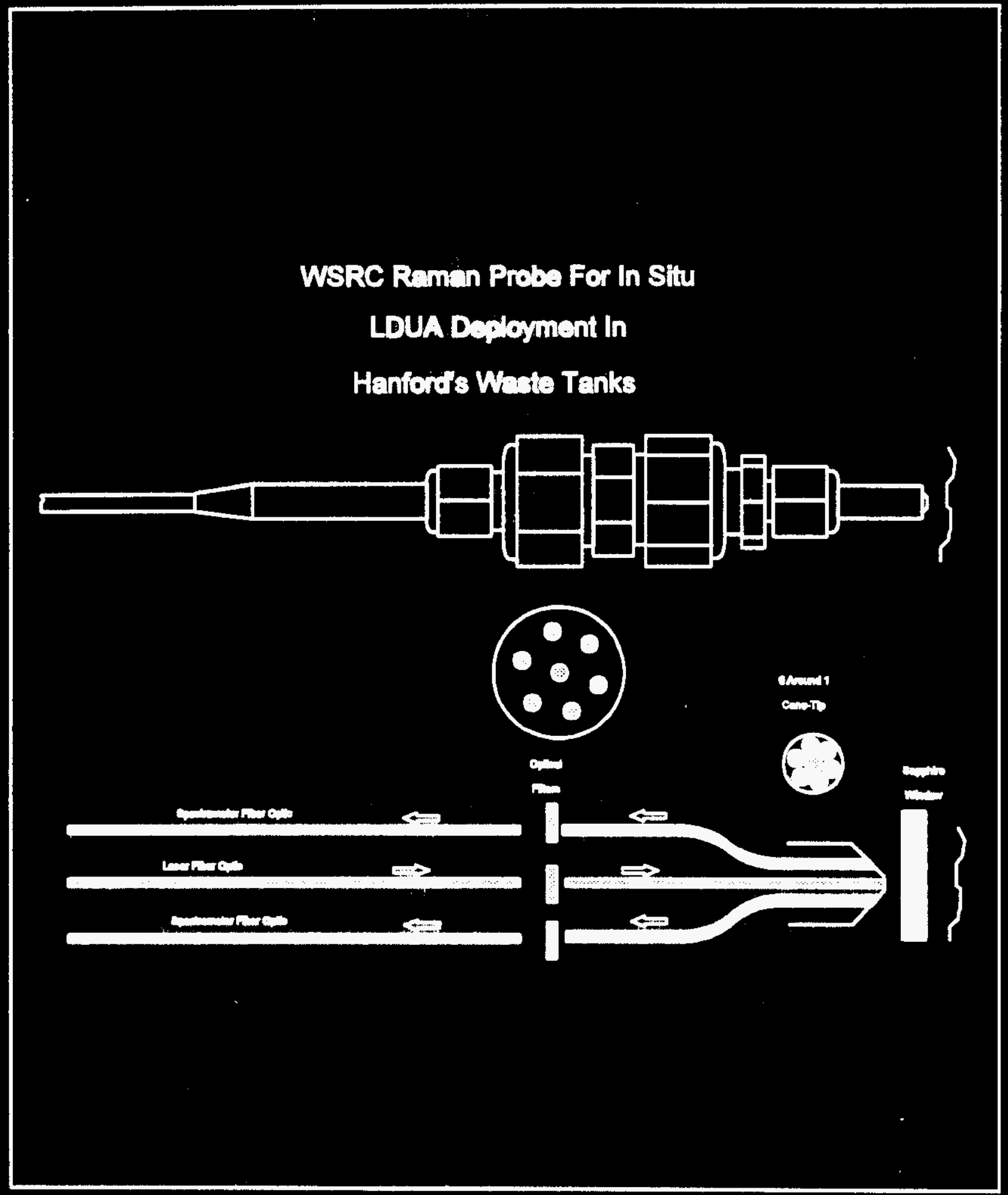


WHC-SD-TD-T1-003, Rev. 0

Figure 2.2. Probe (1): Optieal Deaiga of the WSRC Prototype Raman Probe Head.

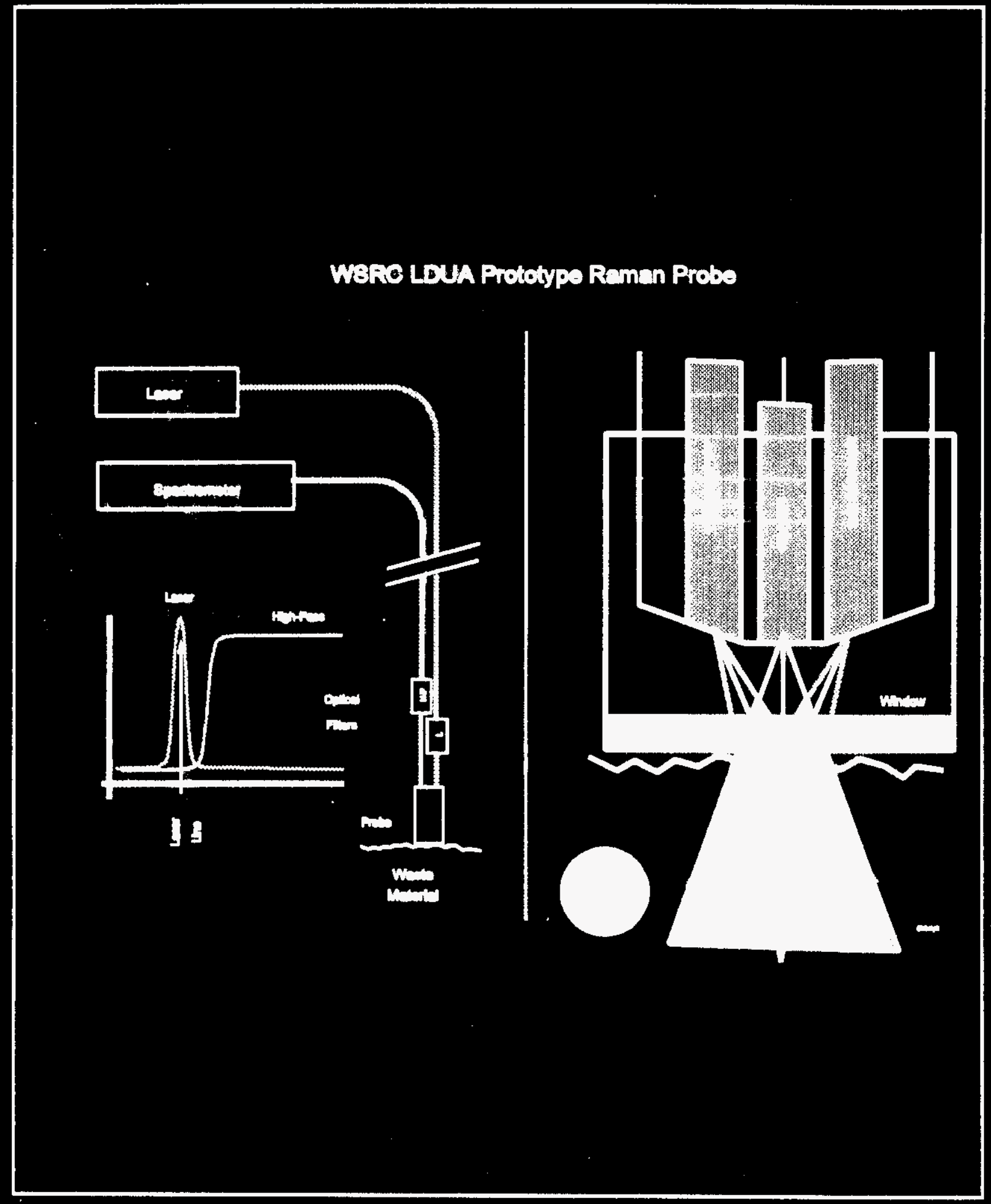


WHC-SD-TD-TI-003, Rev. 0

Figure 2.3. Probe (2): LLNL Flat-Face, 6-Around-1, Fiber-Optic Probe.

Fin Foos Flow Oitle Probe

GAround 1 Fbor Daben
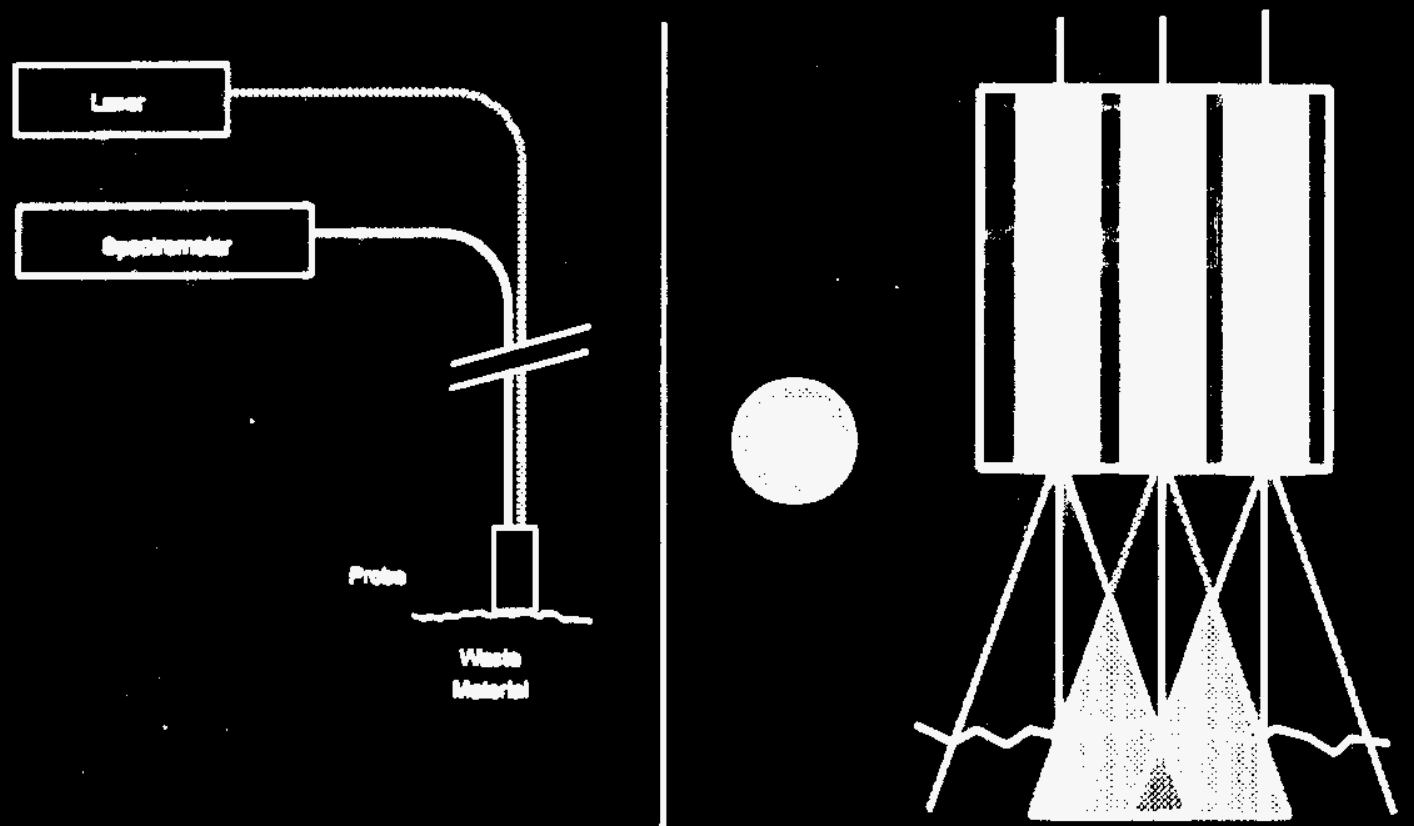
WHC-SD-TD-Th-003, ROv. 0

Figure 2.4. Probe (3): LUNL Flat-Inse, 6-Around-1 Niber-Optic Probe with In-Line Optical Fitters.

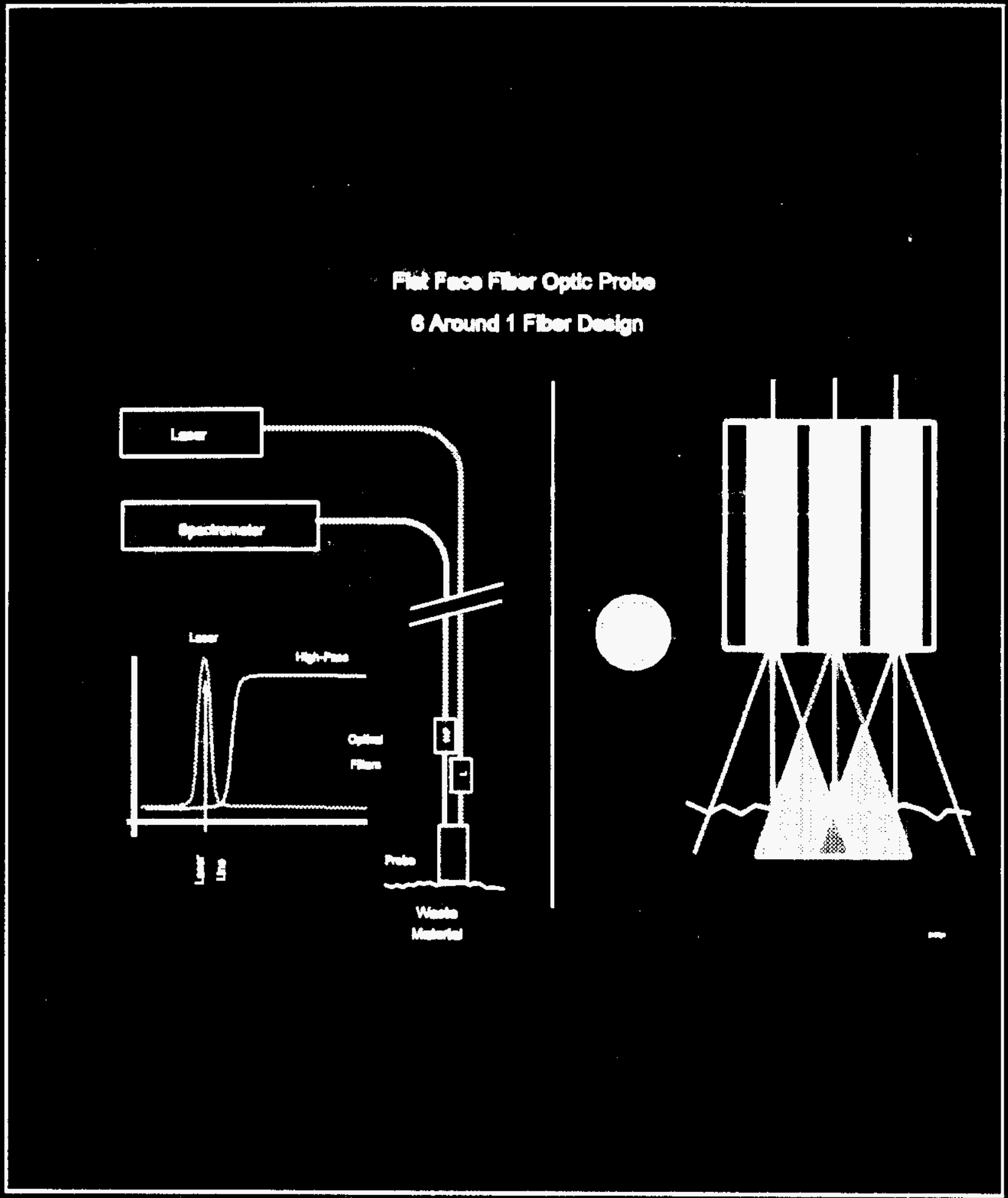


WHE-SO-TD-TI-003, REN. 0

Figure 2.5. Probe-(4): Diffase-Boflectance Probe with In-Line Optical Fitters.

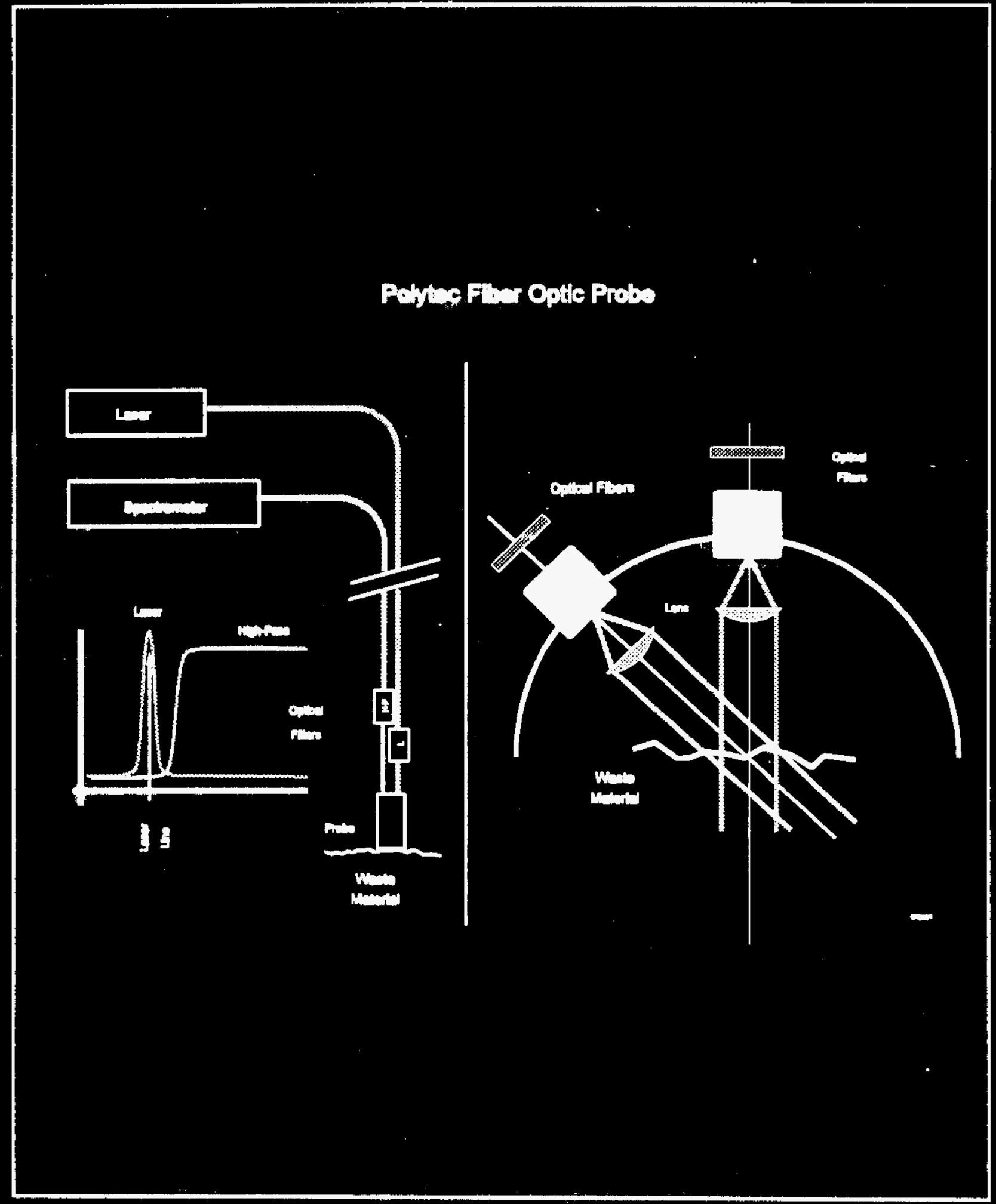




\subsection{Raman Spectroscopy Syatems}

832-nm Syotem: The 532-nm system used an Adlas, Inc., (Stow, MA) model DPY 425II doubled Nd-YAG laser with a maximum output of $c a .400 \mathrm{~mW}$. The spectrograph was a Kaiser Optical Systems, Inc., (Am Arbor, MI) HoloSpec f/1.81 equipped with a "slant-fringe" grating. The spectrograph uses a built-in collimated optical pre-filter stage containing a Kaiser HSPF532AR-2.0 holographic Super-notch Plus ${ }^{\text {TM }}$ filter to reject the Rayleigh line. Figure 2.6 shows the optical layout of both the 532-nm and 785-nm Kaiser spectrographs. Two different chargecoupled device (CCD) imaging detectors were used with this system: a Princeton Instruments, Inc., (Trenton, ND) LN/CCD-1024TKB operated at $-120^{\circ} \mathrm{C}$ or a TEACCD-1152EM/1 operated at $-40^{\circ} \mathrm{C}$. The detectors were controllod by means of a Princeton Instruments ST130 detector controller.

Figure 2.6. Optical Layout of Knicer Optical Systems, Inc., HolaSpec 11.8 Trangmission Grating Spectrograph.

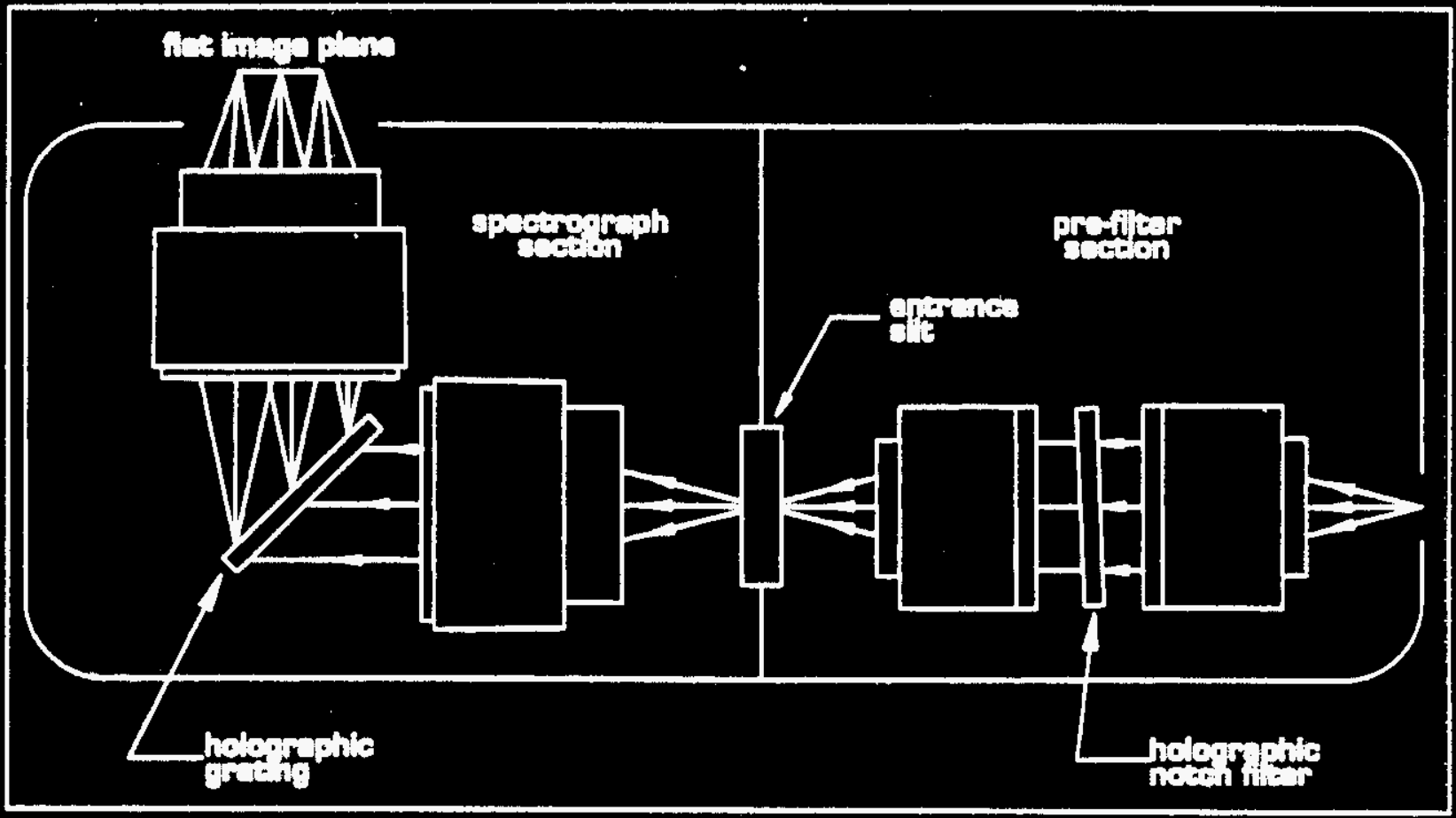


785-nm Syatem: The 785-nm system used an SDL, Inc., (San Jose, CA) model SDL-8630 tunable diode laser with a maximum output of $c a .500 \mathrm{~mW}$ at $785 \mathrm{~nm}$. The laser's power supply and temperature controller was an ILX Lightwave Corp. (Bozeman, MT) model LDC-3900 Modular Laser Diode Controller equipped with a model 39032 thermoelectric temperature controller and model $39400 \mathrm{M}$ current source. The output of the laser was first routed through a $200-\mu \mathrm{m}$ diameter, 1-m long fiber-optic pigtail; the free end of the pigfail consisted of an SMA905 connector containing a 785-nm band-pass dielectric filter to reduce the super-radiant output from the laser. The excitation fiber of the Raman probes tested with the 785-nm system were then comnected to the SMA-905/filter connector. The spectrograph was a Kaiser Optical Systems, Inc., HoloSpec f/1.8i NIR equiped with a"slant-fringe" grating and a Princeton Instruments, Inc., LN/CCD-1024TKB CCD detector operated at $-120^{\circ} \mathrm{C}$. The spectrograph uses a built-in collimated optical pre-filter stage containing a Kaiser HSPF-785AR-2.0 holographic Super-notch Plus ${ }^{\mathrm{TM}}$ filter to reject the Rayleigh line. The detector was controlled by means of a Princeton Instruments ST130 detector controller.

CCD Dotactors: The LN/CCD-1024TKB detector contains an anti-reflection-coated, backilluminated CCD chip with a $1024 \times 1024$ pixel format; the chip active area measures $24.6 \times 24.6$ $\mathrm{mm}$ with a pixel size of $24 \times 24 \mu \mathrm{m}$. The TEA/CCD-1152EM/1 detector contains a front- . illuminated CCD chip with a $1152 \times 298$ pixel format; the chip active arta measures $26 \times 6.7 \mathrm{~mm}$ with a pixel size of $22.5 \times 22.5 \mu \mathrm{m}$. Both detectors are equipped with 16-bit analog-to-digital converters and were operated at $50 \mathrm{KHz}$. Detector binning parameters were set to include only those rows of the CCD that contained the fiber images.

Data Collection: The data-collection computer used with either system was an AST Premmia $4 / 33^{\mathrm{TM}}$ running either Princeton Instrument's CSMA 2.4a software or Florida State University's $R C A L$ software (Mann and Vickers 1994). Data collection and reduction procedures are desicribed in Lopez et al. 1995.

\subsection{Materials and Sample Preparation}

Reagent-grade potassium chloride (used as the target to obtain the probe silica response) and sodium nitrate were dried, milled and pressed into pellets approximately $1 \mathrm{~cm}$ in diameter and 1$\mathrm{cm}$ thick. Other reagents were used as received. Appendix A describes the tank waste simulants. To avoid possible laser-induced sample damage, we mounted the sodium nickel ferrocyanide and tank waste simulant samples on a rotating stage with a rotation rate of $c a$. two revolutions per minute. After mounting the samples on the rotating stage, we used the edge of a rubber policeman to smooth the sample to a uniform thickness, then mounted the fiber-optic probe to allow a one-millimeter spacing between the end of the probe and the surface of the rotating sample. We obtained Raman spectra of liquid samples by immersing the probe directly into the liquid. 


\subsection{Light Sources}

An Oriel Corp. (Stratford, CT) 6032 neon pen lamp provided neon reference lines for wavelength calibration; emissions lines from the laboratory's high-pressure mercury arc lights were also used in conjunction with the neon lamp. A Titan Tool Supply Company, Inc., (Buffalo, NY) model FO-150 tungsten-halogen lamp was the white-light source. We used a 400 watt, high-pressure sodium lamp to simulate the lighting expected in the hot cell. Appendix B contains spectra of the neon wavelength calibration lines at $532 \mathrm{~nm}$ and $785 \mathrm{~nm}$ and the sodium lamp lines obtained with the Kaiser 785-nm system. We obtained reference values for the wavelengths of the mercury, neon, and sodium lines from Phelps 1982 and Zaidel' et al. 1970. 
WHC-SD-TD-TI-003, Rov. 0

This page intentionally blank 


\subsection{RESULTS AND DISCUSSION}

\subsection{2-nm vo. 785-nm Exclation}

\subsubsection{Wavenumber Range and Spectral Resolution}

Table 3.1 compares the spectral ranges and resolutions covered by the 532-nm and 785-nm systems; the 532-nm has the advantage of covering larger Stokes shifts that include NH and $\mathrm{OH}$ stretch regions. The primary limitation of the 785-nm system's spectral range is the poor quantum efficiency of silicon CCD detectors beyond $1050 \mathrm{~nm}$. Appendix C contains comparison Raman spectra of several pure materials and tank waste simulants obtained with both the 532-nm and 785-nm Raman systems.

Table 3.1. Comparisen of Wavelength and Wavenumber Coverage and Resolution for the 532-nin and 785-nm Systems.

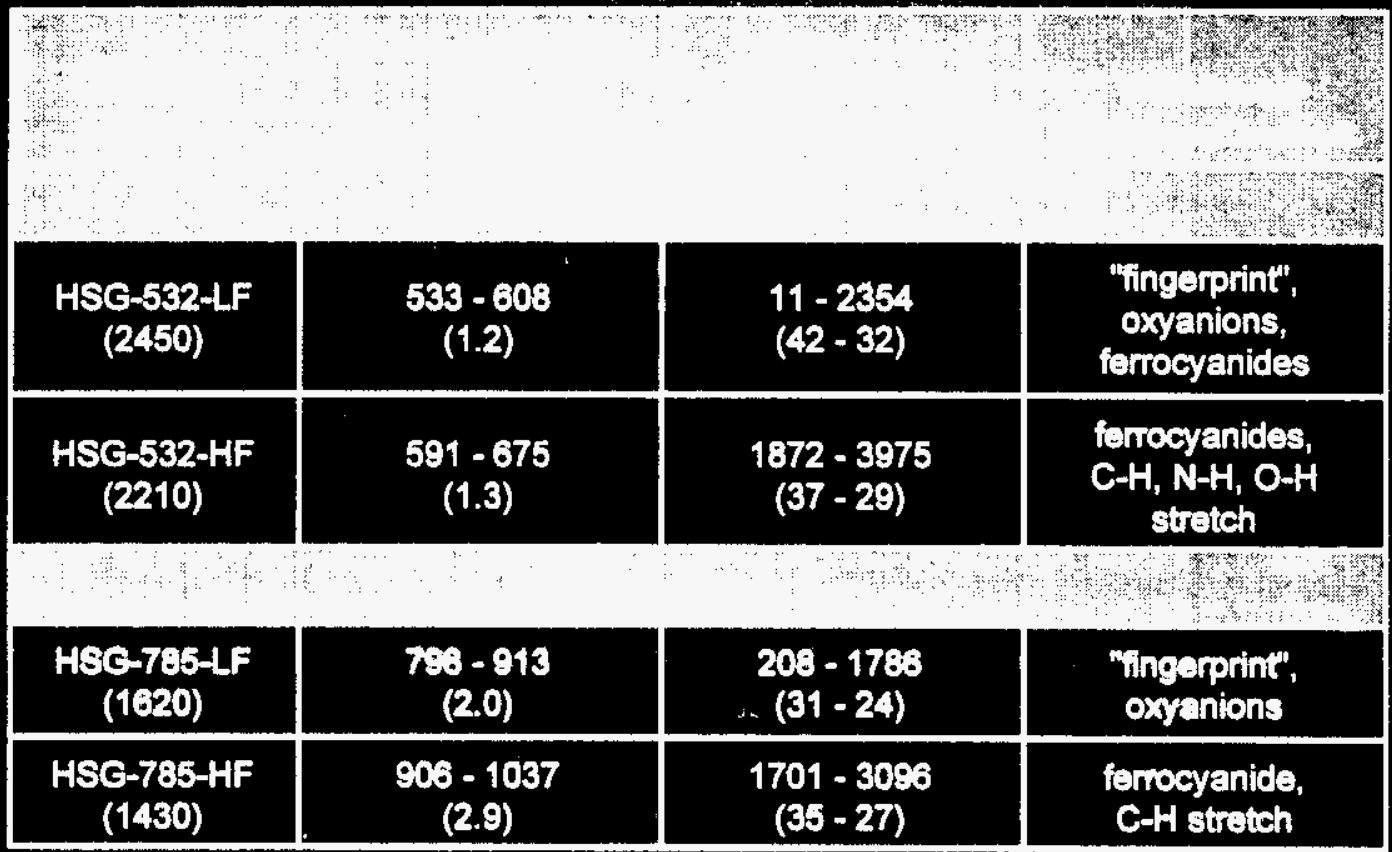

"LF = "low frequency" grating; HF $=$ "high frequency" grating; $g / m m$ = grating line density in grooves per millimeter.

${ }^{b}$ Resolution is defined as twice the peak width at half height for neon atomic lines in the respective window; slit width $=167 \mathrm{\mu m}$.

'When resolution is converted from the wavelength to the Stokes shift domain, spectral resolution improves with increasing wavenumber. 


\subsubsection{Signal-to-Noise Ratios and Detection Limits}

Table 3.2 shows that the sodium nitrate target signal-to-noise ratio of the 785-nm system (equipped with the LN/CCD-1024TKB detector) is not statistically different from that of the 532-nm system (equipped with the TEA/CCD-1152EM/1 detector). Differences in the detectors influence these results somewhat since the $\mathrm{LN}$ detector generates a better signal-to-noise ratio than the TE detector at $532 \mathrm{~nm}$ (see Section 3.3.3 and Table 3.6). The results in Table 3.2 do indicate that factors besides " $v$ " appear to also influence the signal-to-noise ratio characteristics of the system. These factors may include the detector quantum efficiency, the read-out and shot noise characteristics of the silicon CCD detector, the transmission characteristics of the silica fibers, and the optical characteristics of the sample.

Table 3.2. Comparison of Signal-to-Noise Ratios for the 532-nm and 785-nm Systems.

\begin{tabular}{|c|c|c|c|}
\hline & & & \\
& & & \\
& & & \\
\hline 532 & $3731^{b}$ & 104 & 3 \\
\hline 785 & $365^{c}$ & 573 & 8 \\
\hline
\end{tabular}

Signal/noise = baseline-corroeted peak height of the $1067.5 \mathrm{~cm}^{-1}$ sodium nitrate band divided by the standard devintion of the noise on the baseline from ca. 1112 to $1341 \mathrm{~cm}^{-1}$.

-532-nm conditions = WSRC LDUA probe, $22 \mathrm{~mW}$ power at sample, $167-\mu \mathrm{m}$ slits, TEA/CCD-1152EM/1 detector at $-40^{\circ} \mathrm{C}, 60$ second total integration time.

${ }^{0785-n m}$ conditions $=$ WSRC LDUA probe, $39 \mathrm{~mW}$ power at sample, $167-\mu \mathrm{m}$ slits, LN/CCD-1024TKB detector at $-120^{\circ} \mathrm{C}, 60$ second total integration time.

Table 3.3 shows calculated detection limits of various species measured in the simulants. In general, detection limits for nitrate, nitrite, and bismuth phosphate are somewhat better with 785-am excitation (with the LN CCD detector) than with the 532-nm excitation (with the TE CCD detector). The improved detection limits with the 785-nm over the 532-nm system in the oxyanion region probably reflect, to a certain extent, the better noise characteristics of the LN detector, but also may be a function of improved fiber transmission and decreased optical absorption of the simulants in the near-infrared. In contrast, detection limits for sodium nickel ferrocyanide are about the same for the two systems except for the T-Plant bottom simulant: the presence of $0.8 \mathrm{wt} \%$ sodium nickel ferrocyanide in the T-Plant bottom simulant was detected only with the 532-nm system and detected not at all with the 785-nm system. The nearly equal or slightly poorer detection limits of the 785-nm system in the ferrocyanide region are probably due to the rapid drop in detector quantum efficiency in near-infrared region and the etalon effect observed in the LN detector (see Section 3.3.3). 
WHC-SD-TD-TI-003; Rov. 0

Table 3.3. Comparison of Specie Detection Limits for 532-nm and 785-nm Syatems.

\begin{tabular}{|c|c|c|c|}
\hline \multirow{4}{*}{ sodium nitrate } & BY-104 & 2.2 & 0.26 \\
\hline & In-Farm 2 & 0.15 & 0.21 \\
\hline & SY-101 & 0.71 & 0.15 \\
\hline & T-111 top faction & 0.85 & 0.40 \\
\hline \multirow{2}{*}{ sodium nitrite } & $\operatorname{In}-F a m ?$ & 0.74 & 1.1 \\
\hline & SY-101 & 3.6 & 0.60 \\
\hline biemuth phosphate & T-111 bottom frac. & 1.3 & 0.80 \\
\hline \multirow{3}{*}{$\begin{array}{l}\text { sodium nickel } \\
\text { ferrocyanide }\end{array}$} & In-Farm 2 & 0.38 & 0.41 \\
\hline & $\mathrm{T}-111$ top fraction & 0.86 & 0.90 \\
\hline & T-111 bottom frac. & 0.43 & $N D^{d}$ \\
\hline
\end{tabular}

'Detection Limit = $3 \mathrm{x}$ (weight\% specie in sample) $\mathrm{x}$ (spectral baseline standard deviation + baseline-corrected peak height).

b532-nm conditions = WSRC LDUA probe, $22 \mathrm{~mW}$ power at sample, $167-\mu \mathrm{m}$ slits, TEA/CCD-1152EM/1 detector at $-40^{\circ} \mathrm{C}, 300$ second total integration time.

785-nm conditions = WSRC LDUA probe, $27 \mathrm{~mW}$ power at sample, 167- $\mu \mathrm{m}$ slits, LN/CCD-1024TKB detector at $-120^{\circ} \mathrm{C}, 300$ second total integration time.

WD = not detected.

Finally, since some real tank waste samples exhibit fluorescence when illuminated with 514.5-nm laser radiation, we chose the 785-nm system for the examination of real tank waste in the hot cell. In the presence of sample fluorescence, the 785-nm system will likely demonstrate better detection limits than the 532-nm system. 


\subsection{Comparbon of Fiber-Optic Raman Probes}

\subsubsection{Spot Size and Optimal Probe-Sample Distance}

The spot size for the WSRC LDUA probe is approximately $0.8 \mathrm{~mm}$; this is similar to the spot sizes of the other six-around-one probes tested. The Polytec PI probe has a spot size of $4 \mathrm{~mm}$. All spot sizes were measured at the plane of maximum overlap between the excitation and collection fibers.

Figure 3.1 shows the probe response as a function of the distance between the probe and target for three of the fiber-optic Raman probes. The data for these curves were generated by transmitting white light through the excitation fiber of each probe (in the case of the filtered

Figure 3.1. Probe Response as a Function of Probe/Target Separation Distance for Three Fiber-Optic Raman Probes.

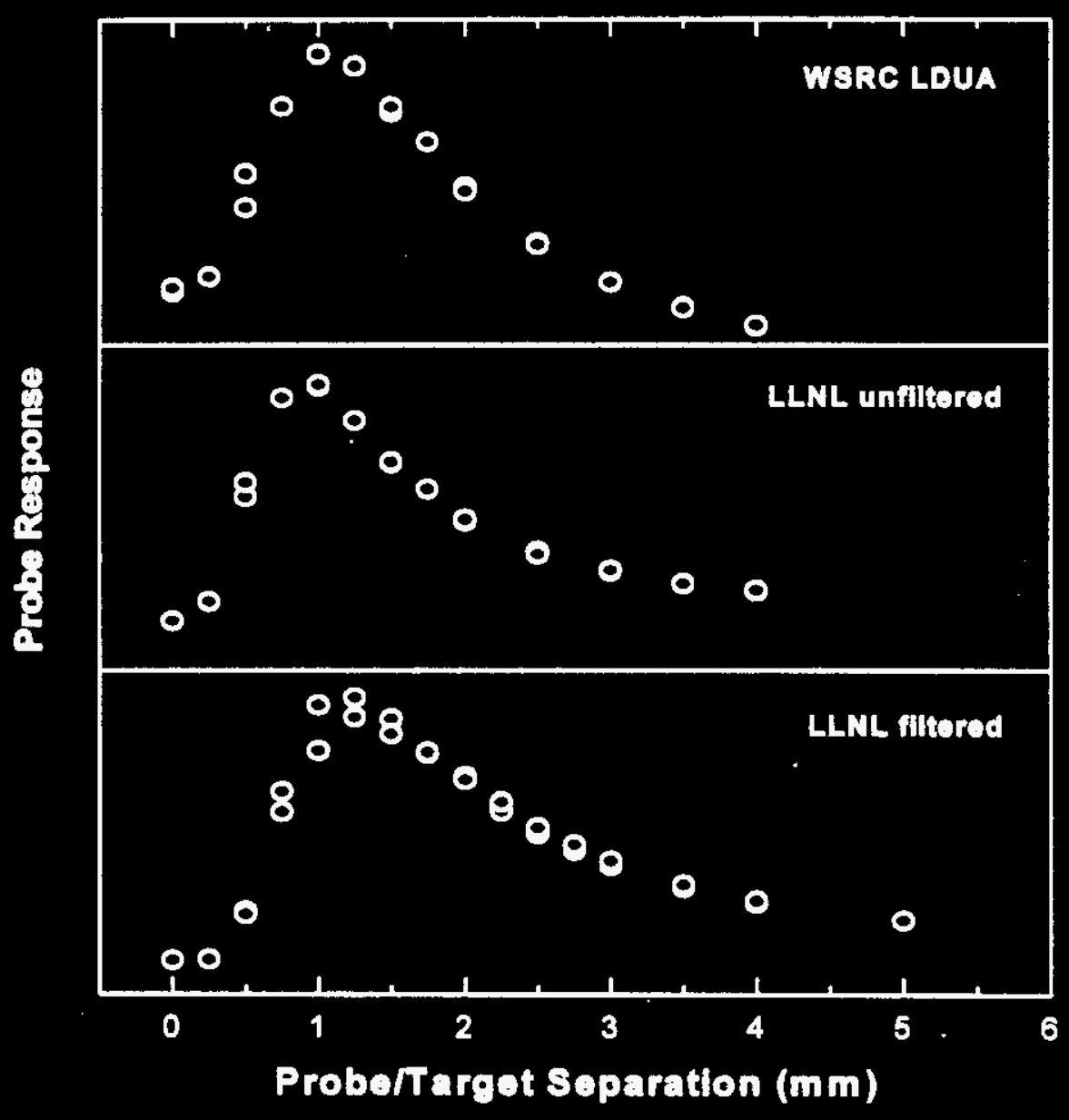


probes, the white light is filtered prior to reaching the target) and aiming the probe at a flat-black surface. Using a vertical axis tratislation stage equipped with a precision micrometer, spectra were taken with the probe first at zero-mm separation from the target, then at incremental probetarget separations to a maximum distance of four or five millimeters. A second set of spectra were then taken in reverse order (decremental probe-target separation) until the probe again contacted the tarjet. Each resuliting spectrum exhibited a broud spectral band; the area under this bend was interested and plotted yersus separation distance to yield Figure 3.1. We did not measure the probe reverwe varas liftof distance performance for the Polytec PI probe since that probe is designed to have maximum excitution-cellection overlap in the plane of the probe's sample-contact tim.

Figure 3.1 shows that all three probes exhibit a maximum response at a probe-target separation of about one mm. Furthermore, optimal probe response is quite critically dependent upon probetarget separation: an error as small as $0.25 \mathrm{~mm}$ in positioning the probe from the target will have appreciable efiect on the probe's response. The WSRC LDUA probe shows different behavior from the two LLNL probes at zero-mm separation from the target." Because of its window, the WSiRC LDUA probe registers some response at zero-mm separtion, whereas the two windowless LLNL probes yielded no response at zero-mm separation.

\subsubsection{Probe Signal-to-Noiee Ratios, Eficiencies, and Nitrate/sillca Peak Ratios}

Table 3.4 compares the four fiber-optic Raman probes tested in this study. Using a sodium nitrate pellet target with a one-mm probe-target separation, three metrics were measured for probe comparison: signal-to-noise ratia, "efficiency", and nitrate/silica peak ratio. Calculations for these charasteristics are outlined in the notes for Table 3.4. In general, the LLNL six-aroundone, flat-face, unfiltered probe provided the best witute signal-to-noise ratio and best efficiency; however, it also produced the poorest nitrate/silica peak ratio. The lack of filters in the LLNL unfiltered probe is the explanation for these results: the unfiltered optical path allows significantly better optical throughput through the probe, but provides no filtering for the silica Raman background generated in the probe.

Conversely, because of optical filtering, the WSRC LDUA probe produced a poorer nitrate signal-to-noise ratio, but a significantly better nitrate/silica Raman ratio, than those of the LLNL unfiltered probe,. The WSRC probe's overall performance is somewhat better than the LLNL 1:6 flat-face filtered probe. There are three design differences between the WSRC LDUA probe and the LLNL filtered probe that may contribute to these performance differences: (1) the WSRC probe has a more efficient conical-tip design than the LLNL flat-face probe, (2) the WSRC probe has 400- $\mu \mathrm{m}$ fiber construction; the LLNL filtered probe has 200- $\mu \mathrm{m}$ fibers, and (3) the WSRC probe has only ca. five $\mathrm{cm}$ of fiber between its tip and filters while the LLNL filtered probe has about $30 \mathrm{~cm}$ between its tip and filters; the longer unfiltered path in the LLNL probe will 


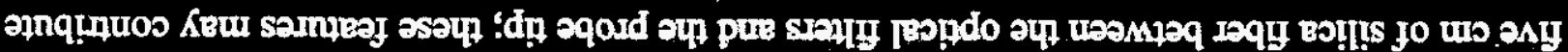

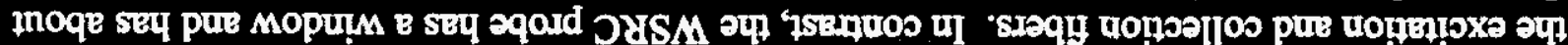

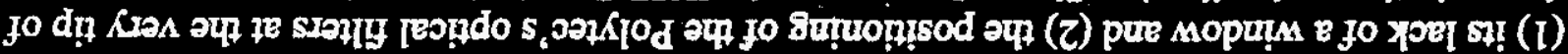

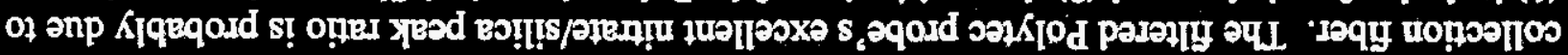

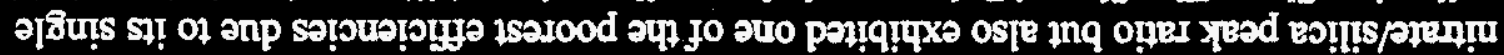

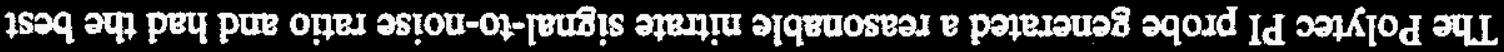

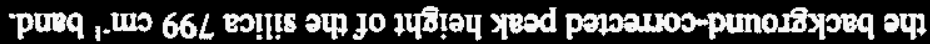

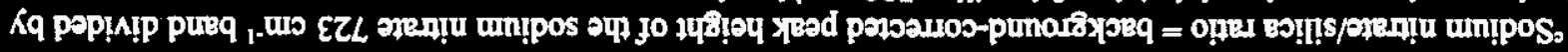

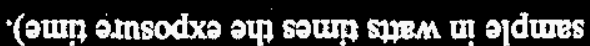
fe LaMod desef) Kq pep!

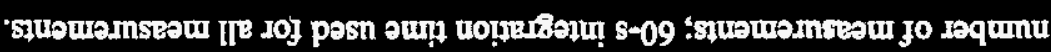

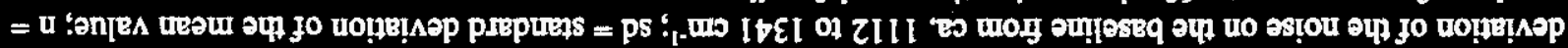

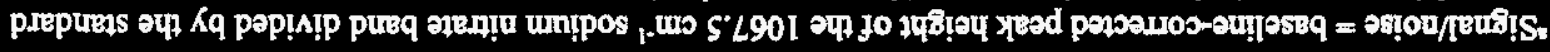

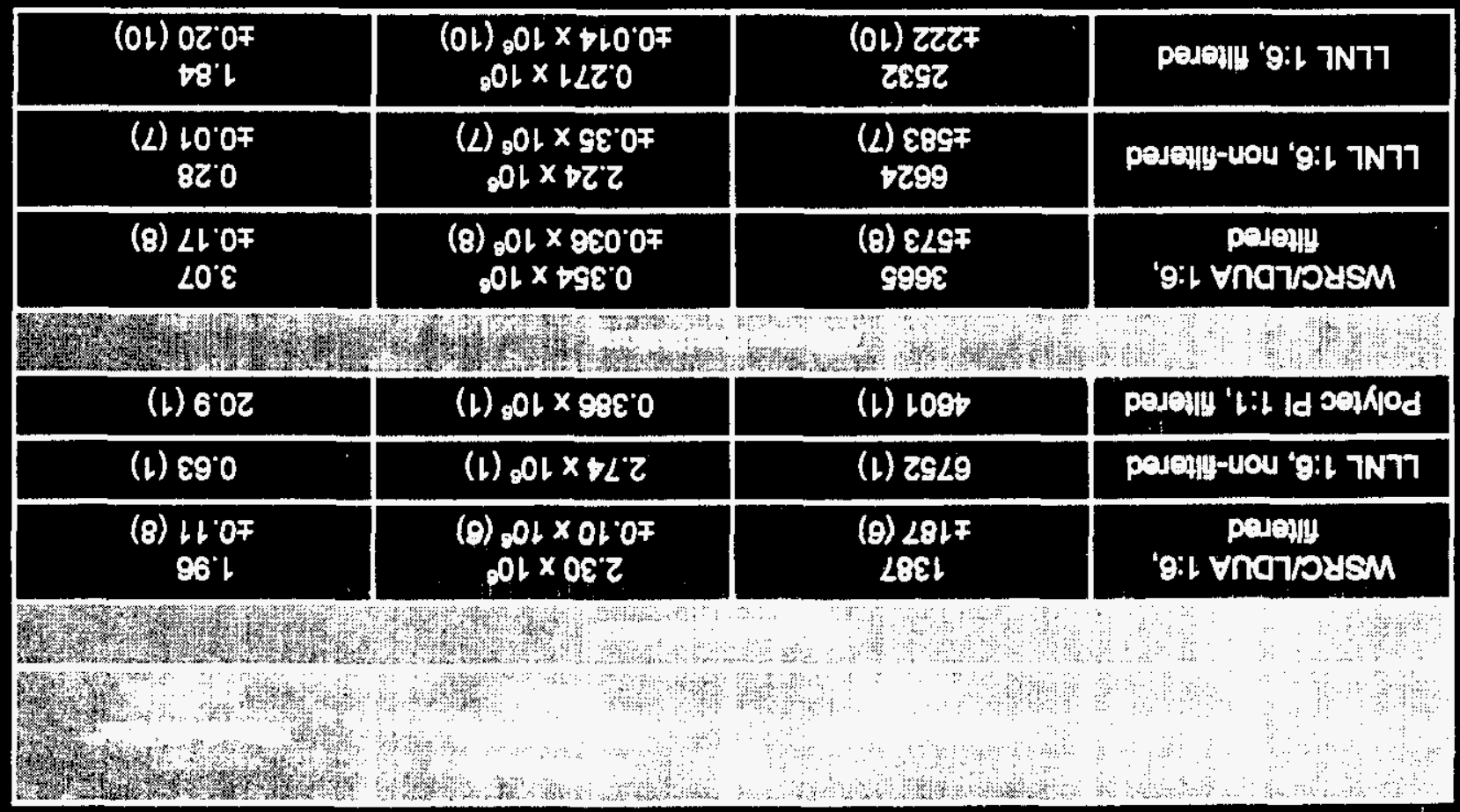

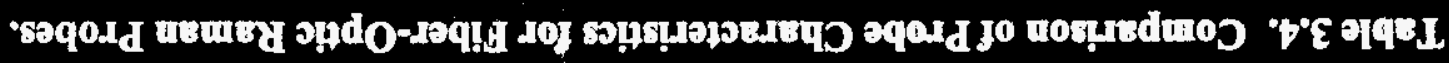

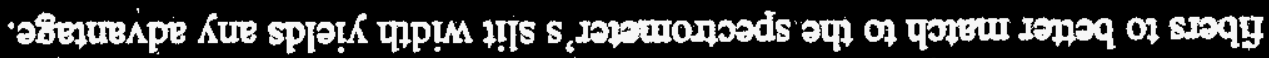

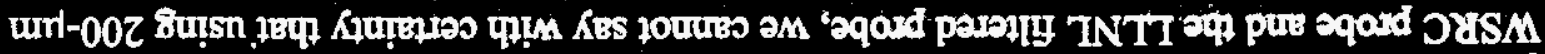

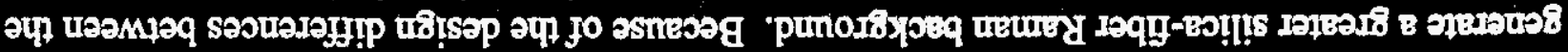


to the poorer nitrate/silica value when compared to the Polytec probe. (The WSRC probe was not designed to allow the probe window to be removed; hence we could not directly test the effect of the WSRC LDUA probe window on the nitrate/silica peak ratio.)

The efficiency for the LLNL unfiltered probe appears to be consistent between the two excitation wavelengths examined, while the efficiencies of the WSRC probe at the two wavelengths differ by an order of magnitude. (In fact, we would predict that efficiency should show a definite wavelength dependence.) The reason for the discrepancy between the efficiency behavior of the two probes at the two different wavelengths is not immediately apparent.

The conclusions from the comparison of these probes are:

(1) Probe-sample distance is critical for optimal probe performance.

(2) Optical filtering greatly improves the sample Raman signal compared to the probe-generated silica signal; filtering should be performed as close to the probe tip as possible for maximum efficacy.

(3) Optical filtering also reduces the throughput of the probe; filtering should be used only as required to remove the silica background from the Raman signal (below ca. $1800 \mathrm{~cm}^{-1}$ ).

(4) Multiple return fibers yield better collection efficiencies.

(5) The presence of a probe window may degrade the silica rejection afforded by optical filtering.

While we performed no studies specifically to determine an optimal excitation-collection spot size for a Raman probe, we can anticipate that larger spot sizes will provide more representative information from heterogeneous tank waste samples. Conversely, larger spot sizes will likely be accompanied by poorer collection efficiencies of the Raman scattered light from the sample.

\subsection{Instrument Operational Performance}

\subsubsection{5-nm Diode Laser}

During the performance of these studies, we used the SDL-8630 diode laser for about 12 hours; we used no optical isolation between the laser and the fiber-optic interface. The laser generated its most stable power output when used in "constant power" operation as opposed to "constant current" mode. We did not directly monitor the frequency stability of the laser during operation; however, we noticed no overt "mode-hopping" during collection of Raman spectra during twoto-four spectral data collection campaigns. The "super-radiant" (non-laser) background output of 
the laser was significant enough that we found it necessary to add a laser-band-pass filter to the output of the laser to reduce laser-generated bagkground in the Raman spectra.

After approximately 12 hours of laboratory operation, the diode laser failed. The failure was characterized by the laser power supply "pegging" at the current limit (1750 $\mathrm{mA}$ ) and low power output ( $2 \mathrm{~mW}$ ). Consultation with SDL, lnc., indicated that the most likely cause of failure was catastrophic failure of the laser diode itself; SDL attributed the failure to lack of optical isolation between the laser and the fiber-optic interface. Consequently, we have designed and will install a Faraday-rotator-based optical-isolator interface botween the repaired laser and its fiber-optic coupling. The interface will also incorporate a holder for a narrow band-pass laser filter, a solenoid-operated shutter, and an XY-tilt fiber-optic positioner with an SMA-905 coupling.

\subsubsection{Kaiser Spectrographs}

The Kaiser HoloSpec $f / 1.8 i$ spectrographs exhibited three advantages over previously used Czerny-Turner (CT) spectrographs. (1) The Kaiser systems exhibited excellent wavelength stability. This feame was most evident during spectral subtractions of probe-silica background from non-silica-corrected Raman spectra; probe-silica backgrounds subtracted cleanly with no residual features indicative of wavelength offsets between the probe-silica reference spectrum and sample Raman spectra. Such offsets were common with the CT Raman systems. (2) The HoloSpec spectrograph has a fast $f /$ number that more closely matches the f/ number of our silica fibers; the low $\mathrm{f} /$ number ensures that the solid-angle output of the fiber-optic is well-matched to the spectrograph.' Properly matchod optics will contribute to (a) minimal signal loss in the optical system and (b) minimal stray light introduced into the detector. (3) The Kaiser systems have a smaller footprint than any of the previously used CT systems; this makes a much more compact total Raman package.

We also noted two problems with the Kaiser spectrographs. (1) The wavelength calibration of the Kaiser system is very non-linear. With the previous CT systems, we obtained excellent leastsquares fits of wavelength to pixel number using, at most, quadratic fits. The Kaiser spectrographs required a cubic fit to obtain, at best, an adequate least-squares fit. Discussions with Kaiser engineers revealed that the holographic gratings used in these systems imposes a sinusoidal variation in wavelength on the detector. Kaiser personnel claim that their HoloGrams ${ }^{\mathrm{TM}}$ software can perform an adequate calibration with their hardware; we have not yet tested this claim in our laboratory. In any event, proper wavelength calibration of the Kaiser system may require more sophisticated calibration methods (e.g. higher-order least-squares fits or piece-wise lower-order fits over short detector regions). 
(2) The Kaiser systems have a built-in detector "wobble plate" to allow adjustment of the detector to the focal plane of the spectrograph. The vendor's literature outlines a procedure to adjust the wobble plate and spectrograph focus for best spectral resolution across the face of the CCD chip. Adjustments to the wobble plate appeared to produce little effect on spectral resolution; we therefore found it difficult to determine if the detector was optimally oriented at the focal plane of the spectrograph. Better procedures will need to be developed to ensure that the detector is optimally positioned at the spectrograph's focal plane to provide maximum spectral resolution.

We also measured the signal-to-noise ratio performance of the 532-nm system at two different slit widths: 167 and $250 \mu \mathrm{m}$; Table 3.5 shows the results. Surprisingly, the $167-\mu \mathrm{m}$ slit yielded a signifioantly higher signal-to-noise ratio than the 250- $\mu \mathrm{m}$ slit. This may be due to reduced stray light or reduced shot noise at the detector when using the narrower slit. Correct selection of slit width requires balancing spestrograph throughput and the sampling rate across the narrowest feature expected in the spectrum (Douglas 1994). While the original recommendation was to maintain a sampling rate of 210 points above a peak's half-height, it appears that sampling rates of from five to six sample points above a peak's half-height is adequate for proper spectral subtraction. Since the 167- $\mu \mathrm{m}$ slit met this sampling rate criterion, we used the $167-\mu \mathrm{m}$ slit for most of the work presented in this document.

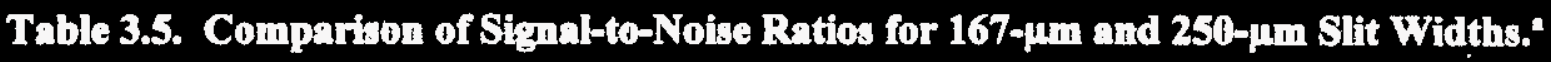

\begin{tabular}{|c|c|c|c|}
\hline 167 & 3731 & 104 & 3 \\
\hline 250 & 1387 & 187 & 6 \\
\hline
\end{tabular}

'All data collected using the WSRC-LDUA 1:6 probe with filters, 532-nm excitation, the TEA/CCD-1 152EM/1 detector, and 60-s total integration times.

bSignal/noise $=$ baseline-corrected peak height of the $1067.5 \mathrm{~cm}^{-1}$ sodium nitrate band divided by the standard deviation of the noise on the baseline from ca. 1112 to $1341 \mathrm{~cm}^{-1}$.

\subsubsection{CCD Detectors}

We tested the two CCD detectors noted in Section 2.2 - a Princeton Instruments, Inc. (Trenton, NJ), LN/CCD-1024TKB operated at $-120^{\circ} \mathrm{C}$ and a TEA/CCD-1152EM/1 operated at $-40^{\circ} \mathrm{C}$. We compared the signal-to-noise ratio characteristics of the two detectors measured using the $1067.5 \mathrm{~cm}^{-1}$ band of sodium nitrate with 532-nm excitation; Table 3.6 lists the results and measurement conditions. The $\mathrm{LN}$ detector has a significantly greater signal-to-noise ratio under 
the measurement conditions employed. We did not perform the same comparison at $785 \mathrm{~nm}$. However, since the LN detector exhibits some etalon behavior at $785 \mathrm{~nm}$ (vide infra), we will make an additional comparison at $785 \mathrm{~nm}$ to determine if the superior sensitivity of the LN detector at long wavelengths outweighs the detector-produced etalon noise.

\section{Table 3.6. Comparison of Signal-to-Noise Ratios for the LN/CCD-1024TKB and T2A/CCD-11525M/1 CCD Detectors."}

\begin{tabular}{|c|c|c|c|}
\hline & & & \\
\hline LNCCD-1024TKa & 2621 & 481 & 3 \\
\hline TENCCD-1169EW/ & 1387 & 187 & 6 \\
\hline
\end{tabular}

'All data collected using the WSRC LDUA 1:6 probe with filters, 532-nm excitation, 250- $\mu \mathrm{m}$ slits, and 60-s total integration times.

bSignal/noise = baseline-corrected peak height of the $1067.5 \mathrm{~cm}^{-1}$ sodium nitrate band divided by the standard deviation of the noise on the baseline from ca. 1112 to $1341 \mathrm{~cm}^{-1}$.

Figure 3.2 shows the white-light spectra for the LN detector obtained with both the 532-nm and 735-nm systems using the various gratings characterized in Table 3.1. The LN detector exhibits a noticeable etalon effect at $785 \mathrm{~nm}$ that is not seen at $532 \mathrm{~nm}$. The etalon effect becomes more pronounced with increating wavelength. Since the etalon pattern is dependent upon the "mix" of wavelengths in the speennin, it will not completely ratio out with white-light spectral correction. Therefore, we can anticipate that the etalon effect, coupled with the detector's decreasing quantum efficiency with increasing wavelength, will cause species with Stokes shifts greater than about $2100 \mathrm{~cm}^{-1}$ to suffer from pocrer detection limits with 785-nm excitation than with 532-nm excitation. The TE detector exhibits no noticeable etalon effect at $532 \mathrm{~nm}$; we have not yet tested this detector at $785 \mathrm{~nm}$ to see to what extent it exhibits etalon effects at longer wavelengths.

While the LN detector has better quantum efficiency than the TE detector at $532 \mathrm{~nm}$, the TE detector does have three advantages over the LN system. (1) The TE detector is thermoelectically cooled and does not require liquid nitrogen. (2) The TE detector has a faster data acquisition rate than the LN system. The LN detector has a latency of about three seconds for every frame of data collected while the TE detector's latency is less than one second. This means that the TE detector can collect spectra faster than the LN system when co-adding large numbers of short-exposure-time spectra. (3) The TE detector is a smaller package and allows a more compact instrument. 
WHC-SD-TD-TI-003, Rov. 0

Figure 3.2. White-Light Spectra for 532-nm and 785-nm Gratings with LN/CCD-1024TKB CCD Detector.

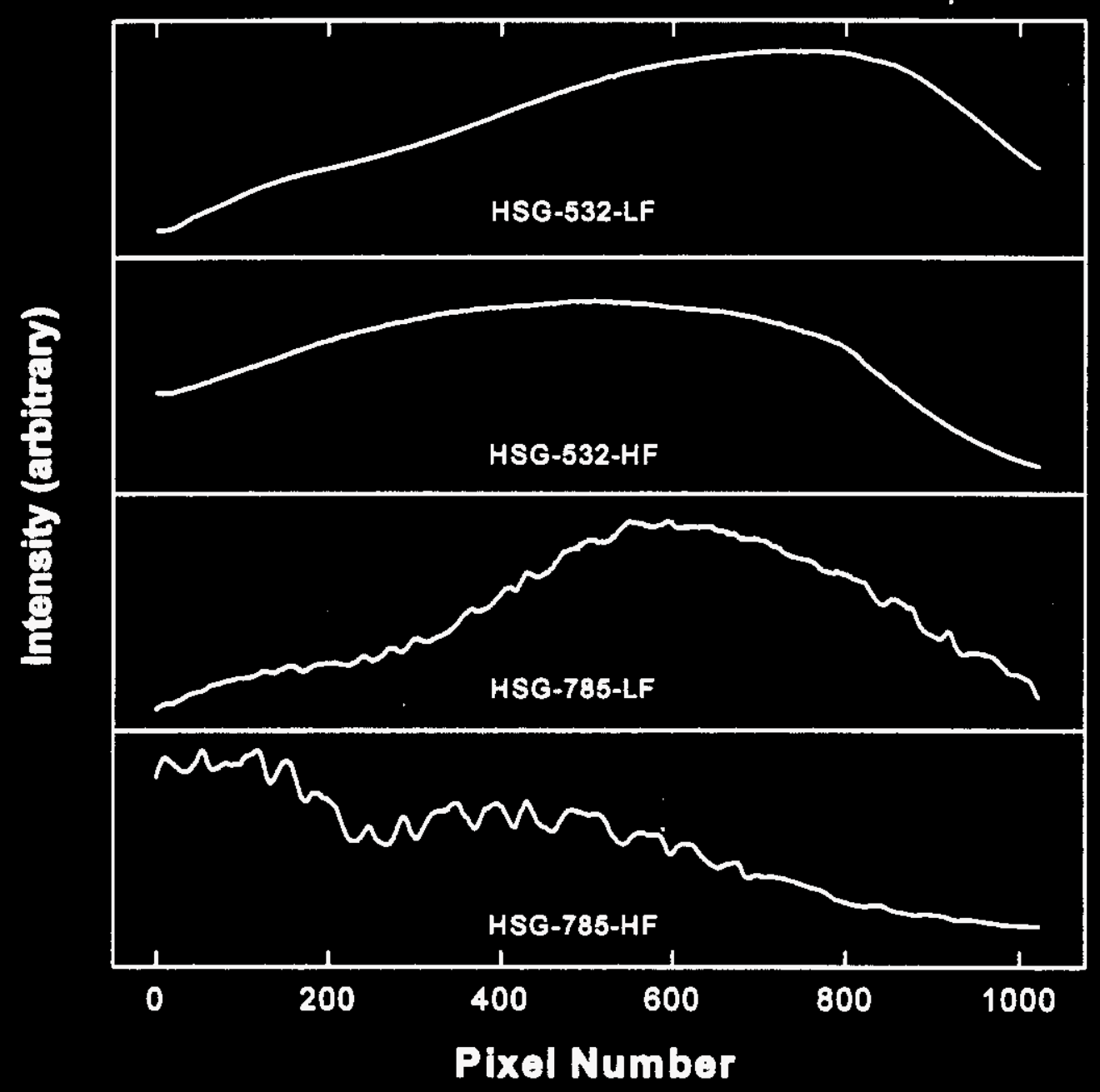

Based on the better signal-to-noise performance of the LN detector using 532-nm excitation and the LN's superior quantum efficiency at long wavelengths, we decided to use the LN detector for the 785-nm system. However, should the difference in signal-to-noise performance for the two detectors be less than about a factor of two at $785 \mathrm{~mm}$, then the TE may be the detector of choice based on its other advantages over the LN detector. 
WHC-SD-TD-TI-003, Rov. 0

This page intentionally blank 


\subsection{CONCLUBIONS AND FUTURE WORK}

\subsection{Concluaions}

\subsubsection{Selection of 785-nm Raman System}

We have determined that the optimal Raman system for the examination of Hanford-Site highlevel waste is a 785-nm system based on an SDL, Inc., laser and a Kaiser Optical Systems, Inc., spectrograph. This decision is based upion

(1) the near-equivalent signal-to-noise ratio and detection limit performance of the 532-nm and 785-nm Raman systems using tank waste simulants,

(2) the likelihood that 532-nm excitation-induced luminescence in some Hanford-Site tank waste samples will "swamp" the Raman signals from those samples; 785-nm excitation should yield better Raman signal-to-noise ratios in the presence of sample luminescence.

(3) the superior wavelength stability of the transmission-grating spectrograph over previously used Czerny-Turner scanning spectrographs.

The major trade-offs in selecting the 785-nm system are

(1) the NH- or OH-stretch regions are accessible with the 532-nm system but not the with 785nm system, and

(2) the signal-to-noise ratio in the CH-stretch region will be somewhat poorer for the $785-\mathrm{nm}$ system than the 532-nm system.

\subsubsection{Probe Selection}

Based on the work presented in this document, the probe should have the following design features:

(1) optical filters placed as close to the probe tip as possible to minimize the probe's silica respense and thus imgrove siganal-tonnoice ratio,

(2) multiple return fibers to yield better collection efficiencies,

(3) no probe window to degrade the silica rejection afforded by the optical filtering, and

(4) some mechanism to accurately and reproducibly position the probe with respect to the sample (for hot-cell operation). 
We would also like a large excitation spot sire (probably $>1 \mathrm{~mm}$ ) to (a) excite a representative area of the sample and (b) reduce possible laser-induced photo-damage to the sample.

Some trade-offs may compromise the final probe design. For example, if it is not feasible to build a mechanism to accurately position the probe with respect to the sample in the hot cell, then a sample-contacting probe with a window may be a necessity. A windowed contact probe, however, generates additional problems besides increased window-generated probe backgrounds; a window that contacts the sample may chemically cross-contaminate the sample as the probe is moved from site to site on the sample. Chemical eross-contamination may affect the accuracy of the Raman data collected from the sample and will require either (1) washing the probe between samples or (2) providing the probe with a protective cover that is disposed between sample points. Either washing or disposable probe covers will generate an undesirable waste stream. Cone penetrometer deployment of a Raman probe will obviously require the use of an optical window; therefore, the issues of probe background response and possible sample carry-over as the penetrometer is pushed into the waste will need to be addressed.

\subsection{Future Work}

A number of issues remain to be addressed before final đeployment of a 785-nm Raman system. These issues fall generally into four categories:

(1) final system optimization

(2) final selection of a probe design,

(3) packaging of the system for deployment, and

(4) selection of software to (a) operate the system and (b) perform data reduction.

\subsubsection{Final System Optimization}

This task will entail testing two variations in the 785-nm system: (1) the use of the TEA/CCD1152EM/1 CCD detector and (2) the addition of a Kaiser Holeplexm grating to the spectrograph. Tests with the TEA detector will allow us to determine how severely the etalon effect evident with the LN/CCD-1024TKB detector affects detection limits. The addition of the Holoplex grating will allow us to gather the complete Ramen spectrum from ca. -50 to $3000 \mathrm{~cm}^{-1}$ with no change in grating and no loss of resolution. 


\subsubsection{Final Selection of Probe Design}

We have received, but not yet tested, a 785-nm probe from Kaiser Optical Systems, Inc., for use with our 785-nm system. This probe has most of the characteristics noted in Section 4.1.2. The probe head is equipped with holographic filters to provide maximum probe-silica signal rejection. The probe can also be equipped with a seven-fiber return bundle (six-around-one design) to maximize Raman signal eollection from the sample. While the probe is normally operated with an optic to focus the excitation spot on the sample, the probe can be operated without the optic to provide a pseudo-collimated excitation and collection region of about five-mm diameter.

\subsubsection{Packaging Raman System for Hot-Cell Deployment}

We must address several issues prior to deployment of the 785-nm Raman system into the hotcell environment:

(1) Probe related issues:

(a) design and build a mechanism to accurately and reproducibly position the probe with respect to the sample,

(b) design and build an ambient light shield to protect the probe from hot-cell lights,

(c) design and build a parking station to hold and protect the probe when not in use;

(2) Attach an optically isolated fiber-optic interface to the 785-nm laser;

(3) Design and build a radiation shield for the CCD detector;

(4) Design and build white-light and neon line reference light sources for hot cell use;

(5) Select chemical references for hot-cell use; design and build holders for references;

(6) Install the Raman system into a final package (e.g. a roll-around cart).

We have already generated conceptual designs to deal with most of these issues. Much of the preliminary work in FY 1996 will be to finish the detailed design and implementation of the conceptual designs.

\subsubsection{Selection of Operating and Data-Reduction Software}

We have three possible choices for data collection software: (1) Florida State University's $R C A L$ software (Mann and Vickers 1994), (2) Princeton Instruments, Inc., WinSpec TM software, and (3) Kaiser Optical Systems, Inc., HoloGrams ${ }^{\mathrm{TM}}$ software. Of these three, only selections (2) and (3) are capable of obtaining spectra from a Kaiser spectrograph equipped with a Holoplex grating. 


\section{WHC-SD-TD-TI-003, Rov. 0}

The HoloGrams software has built-in wavelength calibration routines for use with the Kaiser spectrograph, so that software will probably our first choice for Raman data collection.

To produce interpretable Raman spectra, several data reduction steps are required (Douglas 1994, Lopez et al. 1995). The HoloGrams software is capable of performing most of these steps (e.g. dark-charge correction, white-light ratioing, probe background subtraction, and wavelength calibration). However, more advanced data manipulation techniques, e.g. removal of non-Raman background features (luminescence), spectral smoothing, or factor analysis, are not immediately available in HoloGrams. These advanced functions will require either (1) writing routines in $G R A M S / 386^{\mathrm{m}}$ or (2) exporting data to $R C A L$ routines that can perform these functions. 


\subsection{REFERENCES}

Brown, T. M., S. J. Eberlein, T. J. Kunthara, 1995, Tank Waste Characterization Basis, WHC-SD-WM-TA-164, Rev. 1, Westinghouse Hanford Company, Richland, Washington.

Douglas, J. G., 1994, Qualification Plan for Remote Dispersive Raman Spectroscopic Analysis of Hanford High-Level Waste Samples, WHC-SD-WM-TPI-006, Rev. 1, Westinghouse Hanford Company, Richland, Washington.

Lopez, T., F. R. Reich, J. G. Douglas, 1995, Summary of FY 1994 Raman Spectroscopy Technology Cold Test Activities, WHC-SD-WM-RPT-116, Rev. 0, Westinghouse Hanford Company, Richland, Washington.

Jeppson, D. W., B. C. Simpson, 1994, Characterization and Reaction Behavior of Ferrocyanide Simulants and Hanford Site High-Level Ferrocyanide Waste, WHC-SA-2190-FP, Westinghouse Hanford Company, Richland, Washington.

Jeppson, D. W., J. J. Wong, 1993, Ferrocyanide Waste Simulant Characterization, WHC-EP-0631, Westinghouse Hanford Company, Richland, Washington.

Mann, C. K., T. J. Vickers, 1994, Detection and Quantitative Analysis of Ferrocyanide and Ferricyanide: FY-93 Florida State University Raman Spectroscopy Report, WHC-SD-TD-RPT-010, Rev. 0, Westinghouse Hanford Company, Richland, Washington.

Phelps, F. M., 1982, M. I. T. Wavelength Tables: Volume 2 - Wavelengths by Element, The MIT Press, Cambridge, Massachusetts.

Postma, A. K., J. E. Meacham, G. S. Barney, G. L, Borsheim, R. J. Cash, M. D. Crippen, J. M. Grigsby, D. W. Jeppson, M. Kummerer, J. M. McLaren, C. S. Simmons, B. C. Simpson, 1994, Ferrocyanide Sajety Program: Safety Criteria for Ferrocyanide Watch List Tanks, WHC-EP-0691, Westinghouse Hanford Company, Richland, Washington.

Winkelman, W. D., S. J. Eberlein, 1994, Raman Spectroscopy Peer Review Report, WHC-EP-0785, Westinghouse Hanford Company, Richland, Washington.

Zaidel', A. N., V. K. Prokof'ev, S. M. Raiskii, V. A. Slavnyi, E. Ya. Shreider, 1970, Tables of Spectral Lines, IFI/Plenum Data Corporation, New York, New York. 


\section{WHC-SD-TD-TL-003, Roy. 0}

This page intentionally blank 


\section{APPENDIX A: TANK WASTE SIMULANT CHEMICAL COMPOSITIONS}

We used five tank waste simulants in the work reported in this document. These simulants represent a portion of the range of optical, physical, and chemical properties suspected to be present in real tank westes. Fow sceurately these materials actually simulate the Raman response from real tank waste is yet to be fully determined.

(1) BY-104 saltcake simulant (Table A.1): The BY-104 simulant represents the salt-cake material found on the surface of the waste in tank BY-104. The simulant ranges in color from light tan to brown with increasing water content. The material ranges from a coarse, loosely aggregated sand when dry to a gritty paste when wet.

(2) In-Farm 2 "mixed" simulant (Table A.2): This simulant was generated using the In-Farm ferrocyanide flow sheet (Jeppson and Wong 1993). The sithulant is a translucent, pale blue, gelatinous material.

(3) SY-101 simulant (Table A.3) ; This material simulates the SY-101 tank waste "Window E" sample composition. Tank SY-101 is classified as a complexant concentrate tank. This simulant contains a representative amount of organic carbon in the form of tetrasodium EDTA. The material is a dark olive-drab color with a thin, paste-like consistency containing bits of crystalline material.

(4) T-Plant simulant, top fraction (Table A.4): The T-Plant ferrocyanide flow sheet was used to generate this simulant; the simulant is the top $c a .90$ weight percent of the centrifuged product (Jeppson and Simpson 1994). Actual tank waste produced from the T-Plant flow sheet were originally deposited in the TY tank fam. The simulant is a sludge with a $\tan$ color and the consistency of peanut butter.

(5) T-Plant simulant, bottom fraction (Table A.5): This material is the bottom ca. 10 weight percent of the centrifuged product generated in conjunction with the T-Plant top fraction (Jeppson and Simpson 1994). This simulant is a sludge with a dark tan color and the consistency of peanut butter. 
Table A.1. BY-104 Salt-Cake Simulant Composition.

\begin{tabular}{|c|c|c|}
\hline sodium nitrate & $\mathrm{NaNO}_{3}$ & 81.8 \\
\hline sodium aluminate & $\mathrm{NaAO}_{2}$ & 7.5 \\
\hline sodlum hydroxide & $\mathrm{NaOH}$ & 1.7 \\
\hline sodium sillicate & $\mathrm{Na}_{2} \mathrm{SiO}_{3}$ & 1.5 \\
\hline ferric nitrate & $\mathrm{Fe}\left(\mathrm{NO}_{2}\right)_{\mathrm{s}}$ & 1 \\
\hline scollum phospheste & $\mathrm{Na}_{2} \mathrm{PO}_{4}$ & 0.7 \\
\hline calcium nitrate & $\mathrm{Ca}\left(\mathrm{NO}_{2}\right)_{2}$ & 0.4 \\
\hline magnesium nitrate & $\mathrm{Mg}\left(\mathrm{NO}_{3}\right)_{2}$ & 0.2 \\
\hline mantanese nitrate & $\left.\mathrm{Mn}_{\mathrm{NO}}\right)_{2}$ & 0.2 \\
\hline water & $\mathrm{H}_{2} \mathrm{O}$ & ca. 5 \\
\hline
\end{tabular}

Table A.2. In-Tarm 2 "Mixed" Simulant Composition.

\begin{tabular}{|c|c|c|}
\hline sodium nitrate & $\mathrm{NaNO}_{3}$ & 18.5 \\
\hline sodium phosphate & $\mathrm{NaPO}_{4}$ & 6.1 \\
\hline sodium nituits & $\mathrm{NaNO}_{2}$ & 5.3 \\
\hline disodium nickel ferrogyanide & $\mathrm{Na}, \mathrm{NIFe}(\mathrm{CN})_{2}$ & 10.8 \\
\hline sodium suliate & $\mathrm{Na}_{2} \mathrm{SO}_{4}$ & 1.8 \\
\hline calcium nitrate & $\mathrm{Ca}\left(\mathrm{NO}_{3}\right)_{2}$ & 0.53 \\
\hline sodium hydroxide & $\mathrm{NaOH}$ & 0.003 \\
\hline bound water & $\mathrm{H}_{2} \mathrm{O}$ & 2.7 \\
\hline free water & $\mathrm{H}_{2} \mathrm{O}$ & 54.4 \\
\hline
\end{tabular}




\section{$\varepsilon-\forall$}

\begin{tabular}{|c|c|c|}
\hline 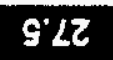 & (eay) $0^{2} H$ & Jelam eay \\
\hline 802J1 & Y(ON) HS & อrapu wnguans \\
\hline eopll & ONB5 & อpany unger \\
\hline 802al & pouz & epuojus 247 \\
\hline 10 & SBN & oplony whpos \\
\hline 10 & OHO. 4 ONIN & omin pexp \\
\hline 10 & $0^{4} \mathrm{H}^{-4} \cdot(20 N) 80$ & opryu un 90 \\
\hline 20 & $0146 \cdot \%(\mathrm{ON}) \mathrm{ey}_{\mathrm{y}}$ & कвभu हायе \\
\hline 90 & OSTN & enaphs unpes \\
\hline 6.0 & ONX & लрmp ung tod \\
\hline$\overline{\varepsilon ! l}$ & DEN & CProptp witpes \\
\hline 92 & O'HZL. Od'BN & 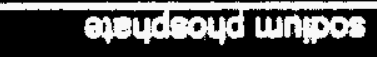 \\
\hline 28 & $0^{2} 16 \cdot 8(\mathrm{ON}) \mathrm{HO}$ & काтіu un!wayp \\
\hline 99 & $\begin{array}{c}\text { OAZ } \\
\text { - VIOG'EN }\end{array}$ & 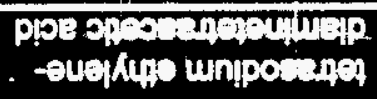 \\
\hline$\angle 9$ & O03N & बांToqpes unpos \\
\hline 12 & HOBN & сркорич широв \\
\hline 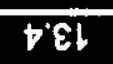 & ONTN & कागय Uा:03 \\
\hline $9+1$ & OHZ - OIVEN & 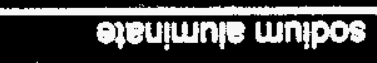 \\
\hline 291 & ONEN & enmu Un!pos \\
\hline
\end{tabular}

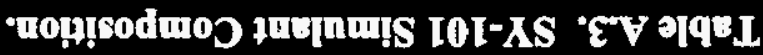




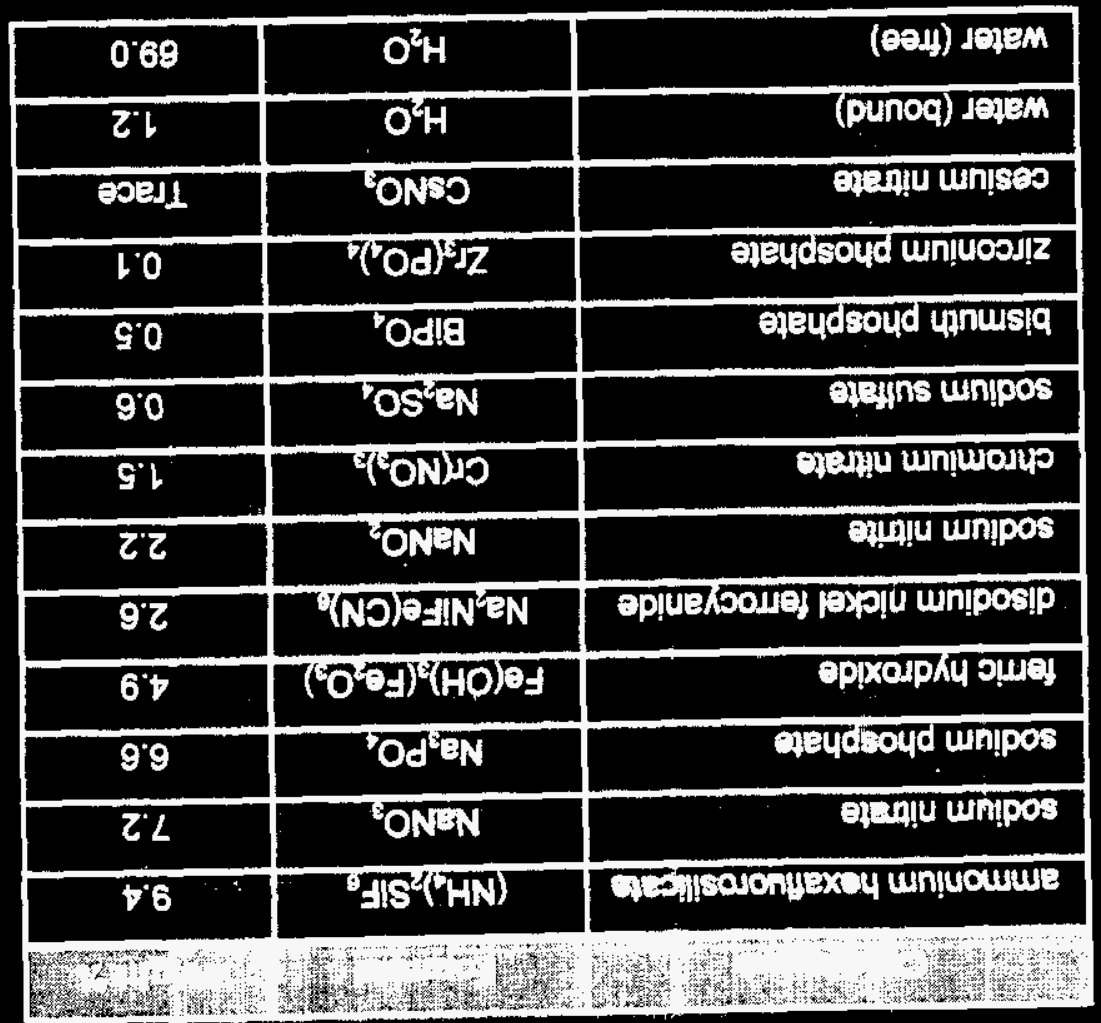

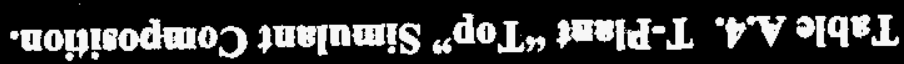


Table A.5. T-Plant "Bottom" Simulant Composition.

\begin{tabular}{|c|c|c|}
\hline bismuth phosphate & $\mathrm{BiPO}_{4}$ & 31.2 \\
\hline anmonium hexanuorocilicate & $\left(\mathrm{NH}_{4}\right)_{2} \mathrm{SiF}_{6}$ & 5.2 \\
\hline sodium nitrate & $\mathrm{NaNO}_{3}$ & 2.5 \\
\hline ferric hydroxide & $\mathrm{Fe}\left(\mathrm{OH}_{h}\right.$ & 2.1 \\
\hline disodium nickel ferrooyanide & $\mathrm{Na}, \mathrm{NHFe}\left(\mathrm{CN}_{k}\right.$ & 0.8 \\
\hline sodium nithe & $\mathrm{NaNO}_{2}$ & 0.8 \\
\hline chromium nitrate & $\mathrm{Cr}\left(\mathrm{NO}_{3}\right)_{3}$ & 0.7 \\
\hline sodium sulfate & $\mathrm{Na}_{2} \mathrm{SO}_{4}$ & 0.3 \\
\hline zirconium phosphate & $\mathrm{Z}_{\mathrm{r}_{3}}\left(\mathrm{PO}_{4}\right)_{4}$ & 0.3 \\
\hline cecium nitrate & $\mathrm{CsNO}_{3}$ & Trace \\
\hline water (bound) & $\mathrm{H}_{2} \mathrm{O}$ & 0.6 \\
\hline water (free) & $\mathrm{H}_{2} \mathrm{O}$ & 45 \\
\hline
\end{tabular}


WHC-SD-TD-TI-003, Rov. 0

This page intentionally blank

A-6 
WHC-SD-TD-TI-003, Rev. 0

\section{APPENDIX B:}

NEON CALIBRATION AND SODIUM-VAPOR LAMP SPECTRA

8-1 


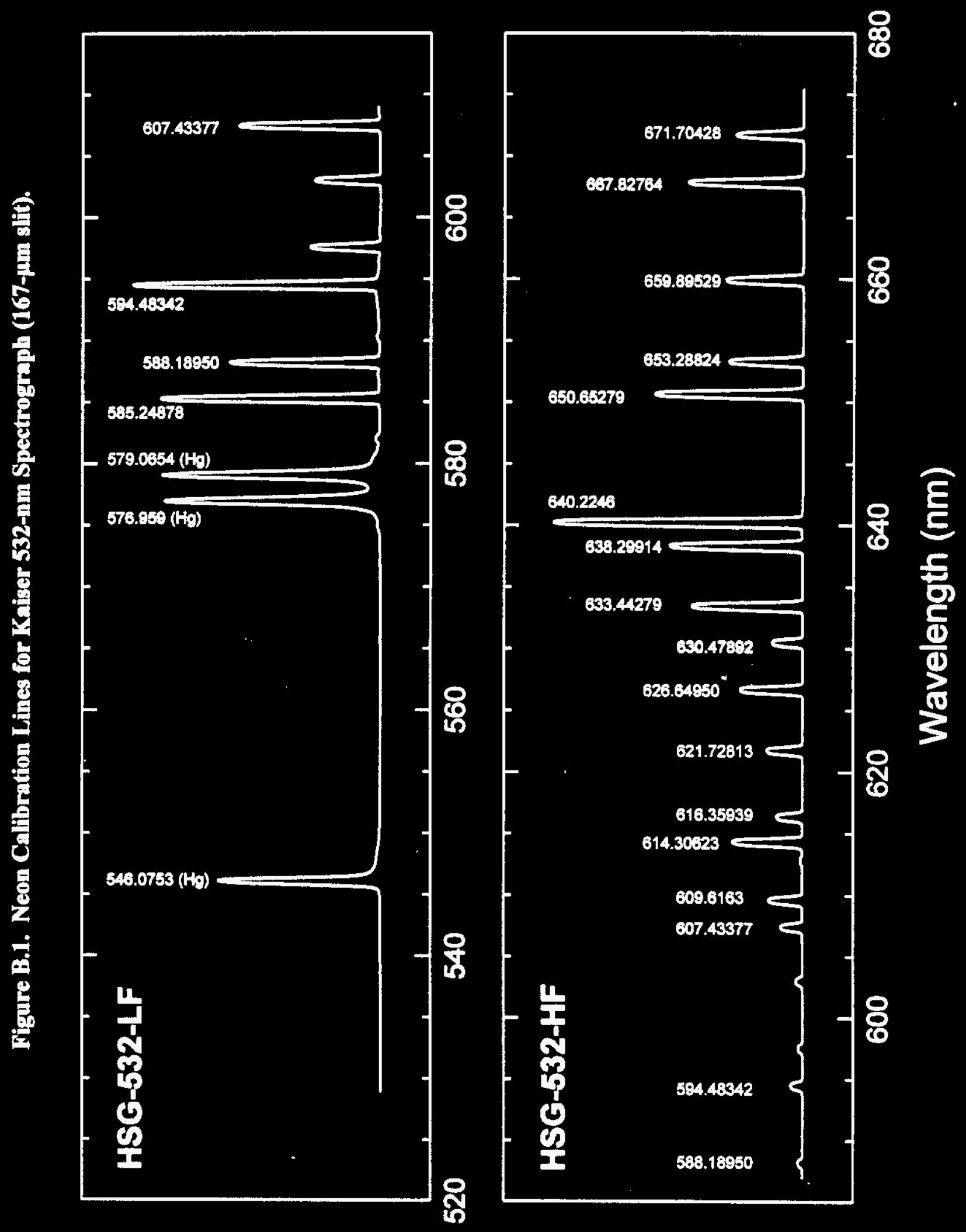

B-2 
WHC-SD-TD-TI-003, Rov. 0

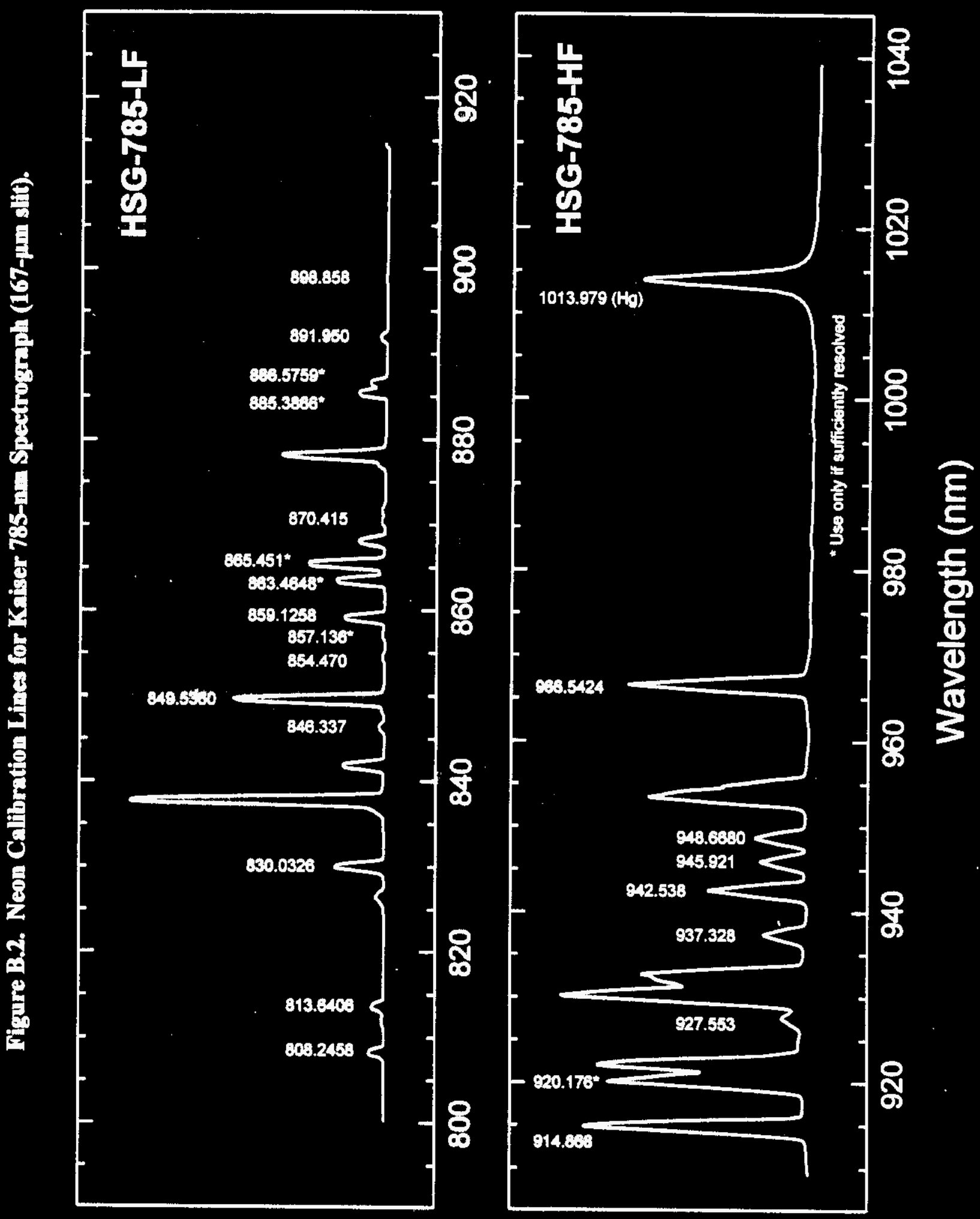


Figure B.3. Spectrum of High-Pressure Sodium Vapor Lamp: 800 - $920 \mathrm{~nm}$.

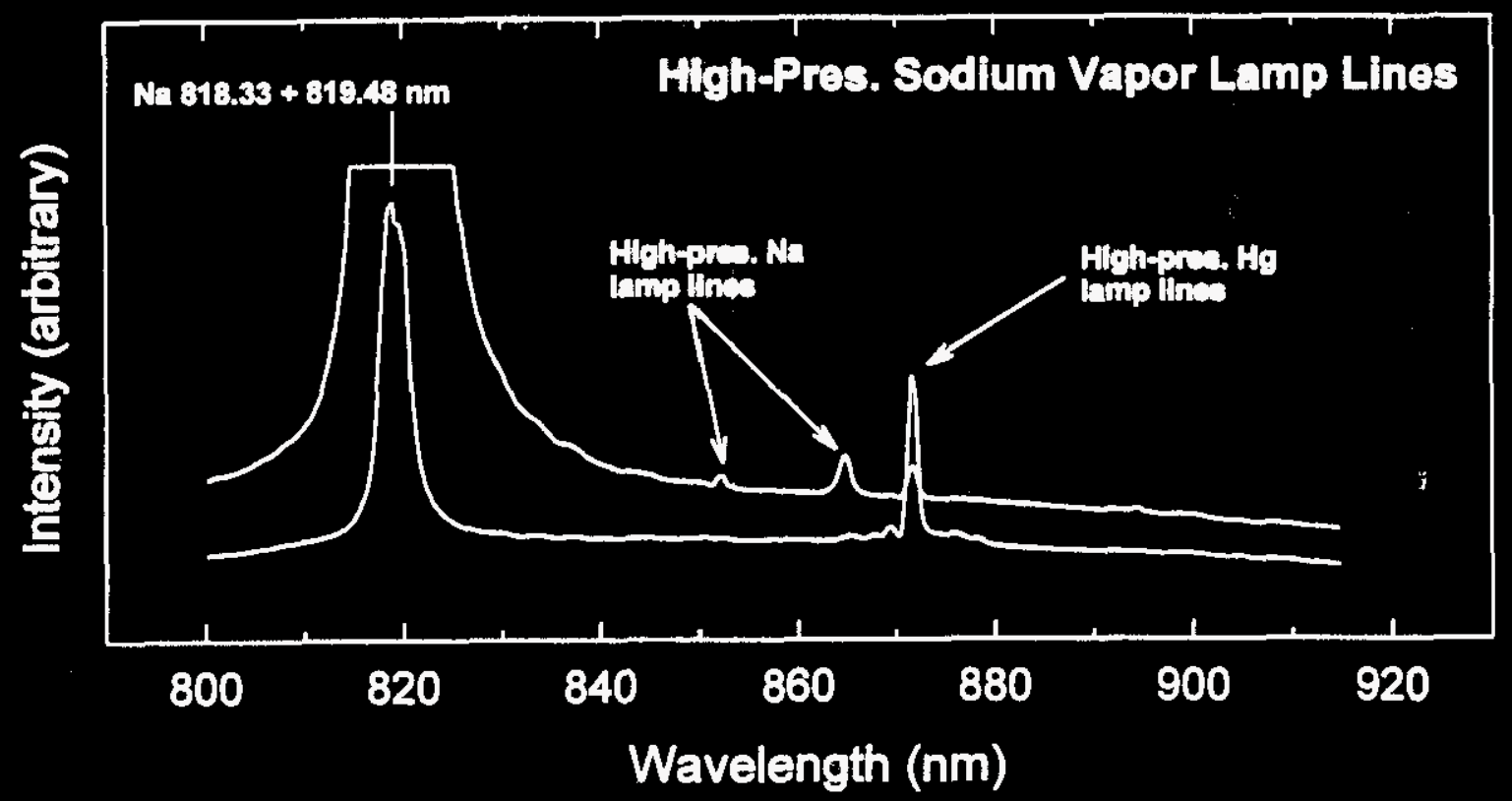

Figure B.4. Spectrum of Elgh-Preasure Sodium Vapor Lamp: 910 - $1040 \mathrm{~nm}$.

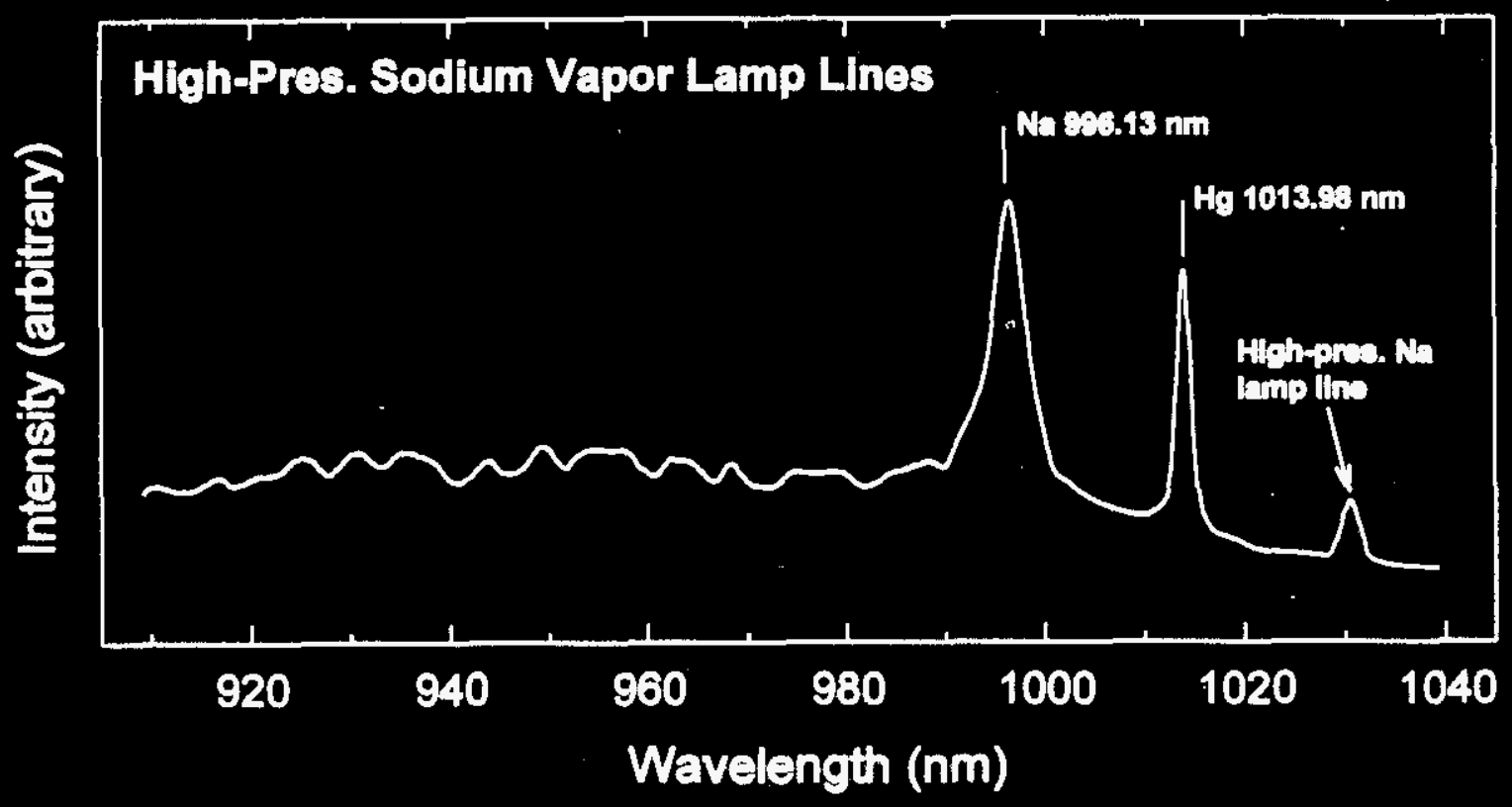




\section{APPENDIX C: RAMAN COMPARISON SPECTRA AT 532 NM AND $785 \mathrm{NW}$}

\section{Experimental Conditions}

Table C.1 outlines the experimental conditions used to collect the data shown if Fgures C.1 - C.9.

Table C.1. Experimental Conditions for Figures C.1 - C.9.

\begin{tabular}{|c|c|c|}
\hline Lest & $\begin{array}{l}\text { Adlss, Inc., DPY } 42511 \text { doubled Nd- } \\
\text { YAC }\end{array}$ & SDL, Inc., SDL-8830 tunable diode \\
\hline Probo & $\begin{array}{l}\text { WSRC LDUA 1:6 with 532-nm } \\
\text { optical filter set }\end{array}$ & $\begin{array}{l}\text { WSRC LDUA 1:6 with 785-nm } \\
\text { optical filter set }\end{array}$ \\
\hline Leser powsr at cample & $22 \mathrm{~mW}$ & $27 \mathrm{~mW}$ \\
\hline Epotronster & $\begin{array}{l}\text { Kaiser Optical Systems, Inc., } \\
\text { Holospec } / 11.8 i\end{array}$ & $\begin{array}{l}\text { Kaiser Optical Systems, Inc., } \\
\text { HoloSpec } 1 / 1.81 \text { NIR }\end{array}$ \\
\hline Silt widith & $167 \mu \mathrm{m}$ & $167 \mu \mathrm{m}$ \\
\hline Gratings & $\begin{array}{l}\text { HSG-532-LF }\left(200-2400 \mathrm{~cm}^{-1}\right) \\
\text { HSG-632-HF }\left(1750-4000 \mathrm{~cm}^{-1}\right)\end{array}$ & $\begin{array}{l}\text { HSG-785-LF }\left(450-1800 \mathrm{~cm}^{-1}\right) \\
\text { HSG-785-HF }\left(1770-3100 \mathrm{~cm}^{-1}\right)\end{array}$ \\
\hline Dotector & $\begin{array}{l}\text { Princoton Instruments, Inc., } \\
\text { TEACCD-1152EW/1 at }-40^{\circ} \mathrm{C}\end{array}$ & $\begin{array}{l}\text { Princeton Instruments, Inc., } \\
\text { LN/CCD-1024TKB at }-120^{\circ} \mathrm{C}\end{array}$ \\
\hline Total interotion timen & $300 \mathrm{sec}$ & $300 \mathrm{sec}$ \\
\hline
\end{tabular}

Total integation time for spectra of sodium nitrate, acetonitrile, and cyclohexane is 60 seconds. 
WHC-SD-TD-TI-003, Rov. 0

Figure C.1. Sodium Nitrate Raman Spectra Using 532-nm and 785-nm Ereitation.

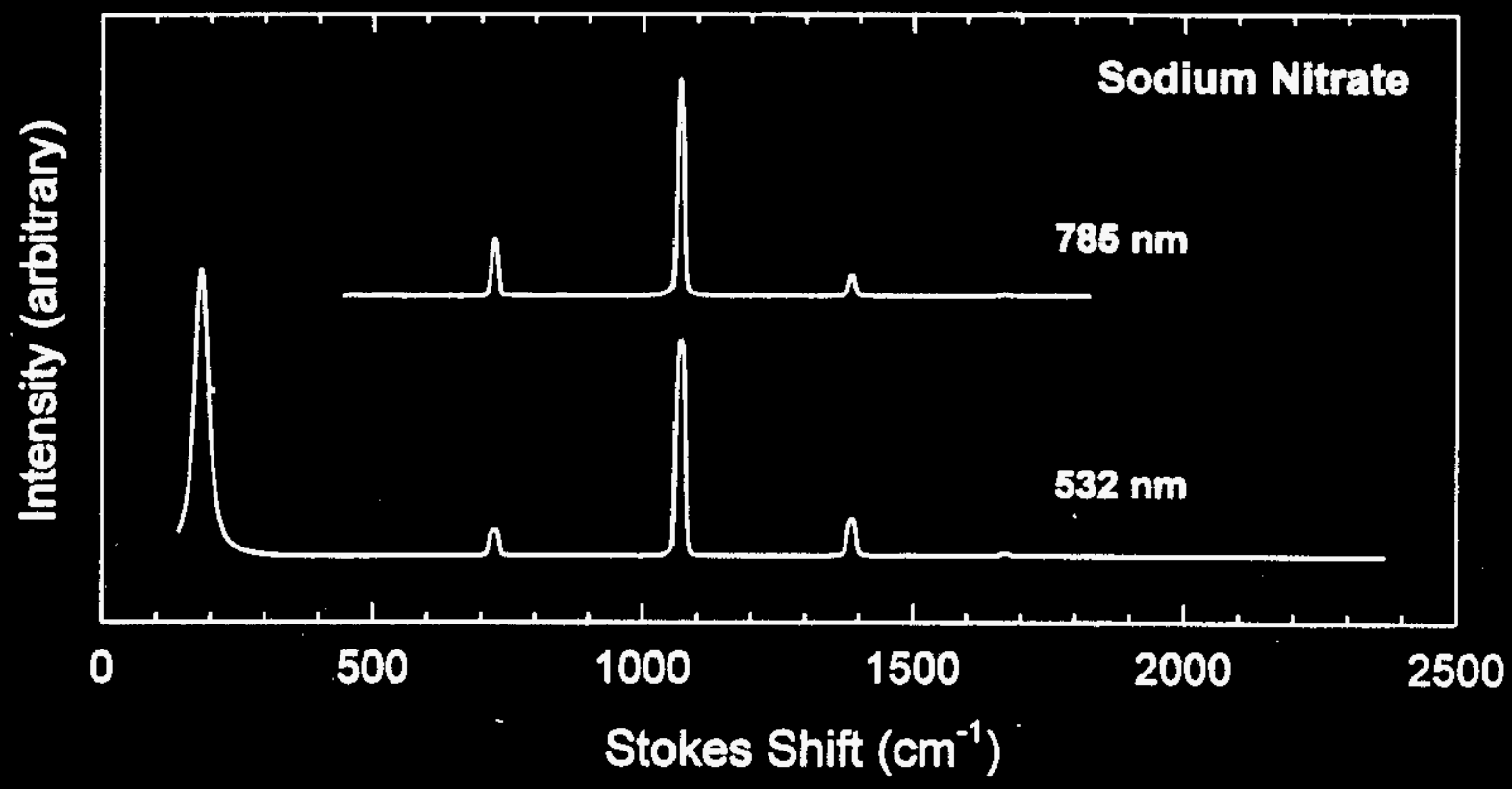

Figure C.2. Acetonitrile Raman Speetra Using 532-nm and 785-am Excitation.

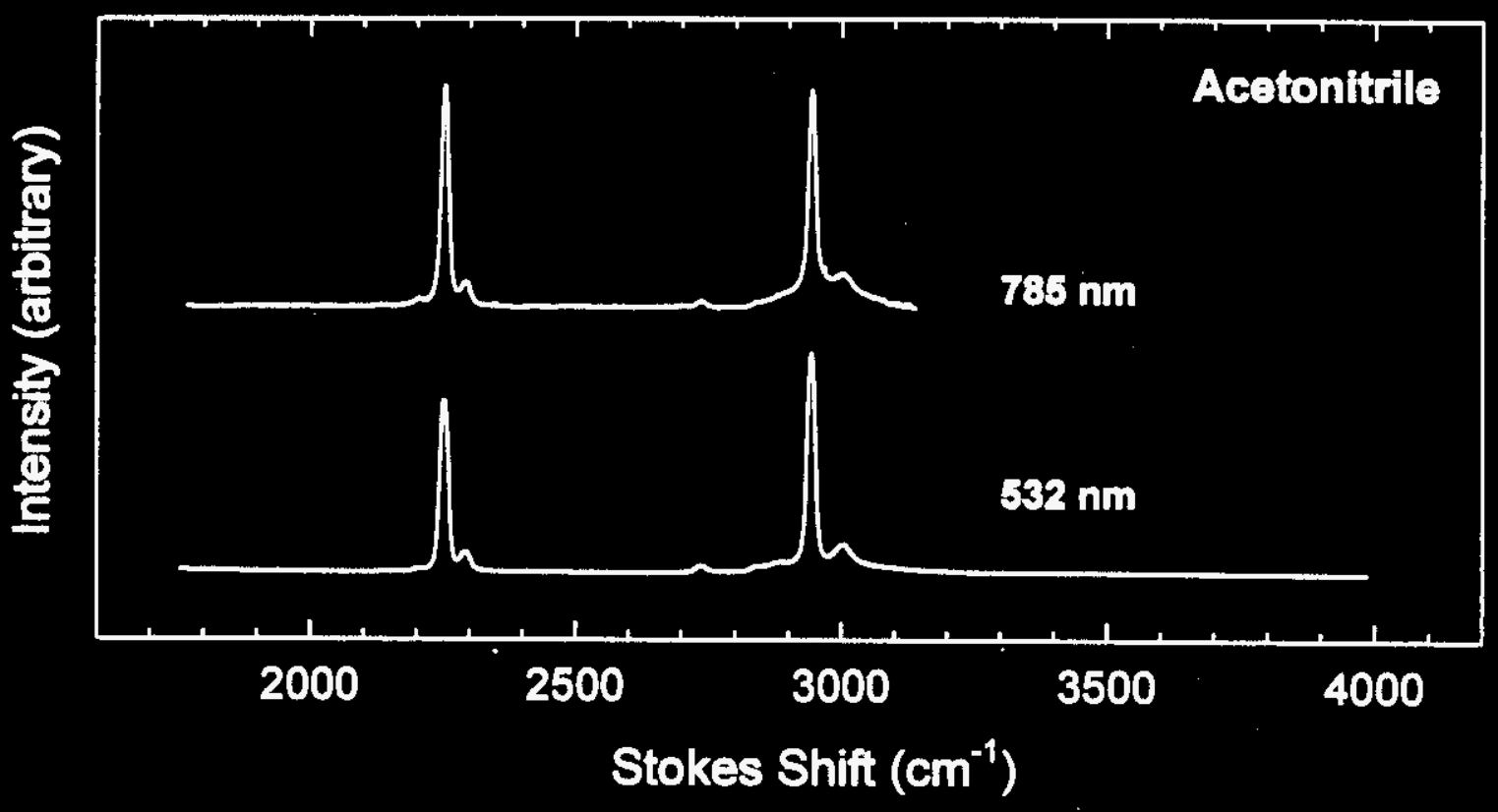

C-2 
WHC-SD-TD-TL-003, ROV. 0

Figure C.3. Cycloherane Raman Spectra Using 532-nm and 785-nm Excitation.

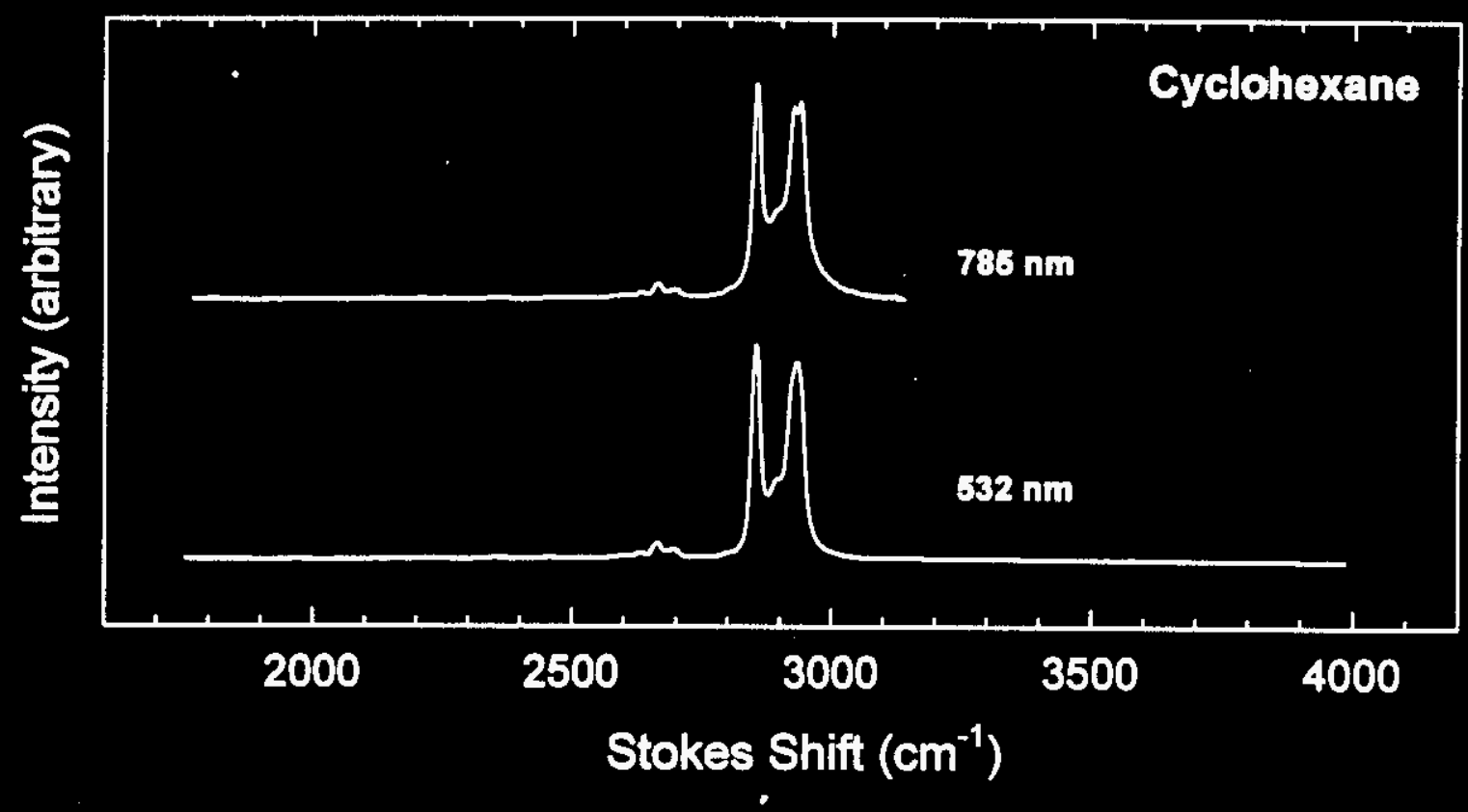

Figure C.4. Sodium Nickel Ferrocyanide Raman Spectra Using 532-nm and 785-nm Exceitation

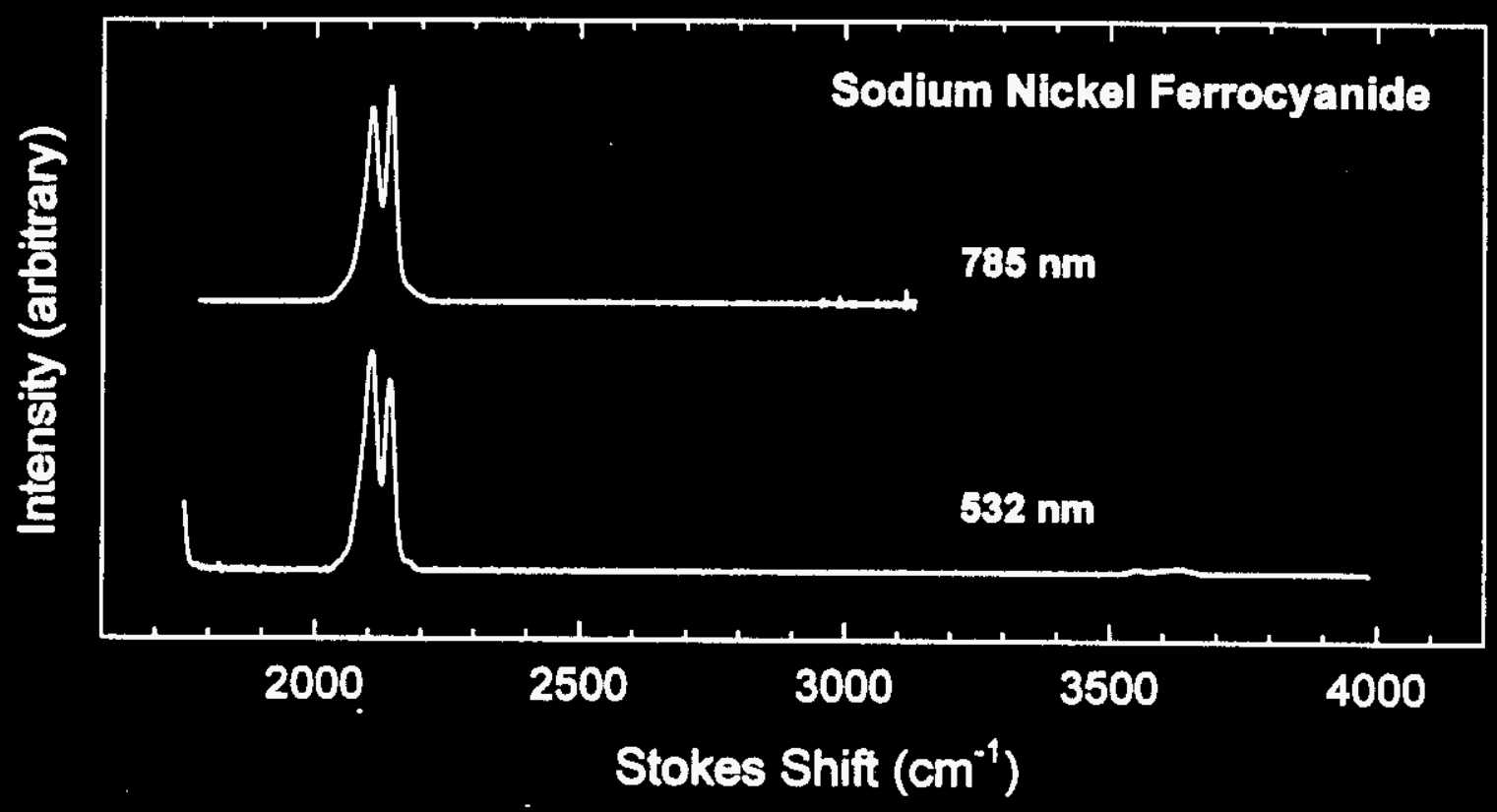


WHC-SD-TD-TI-003, Rov. 0

Figure C.5. BY-104 Simulant Raman Spectra Using 532-nm and 785-nm Excitation.

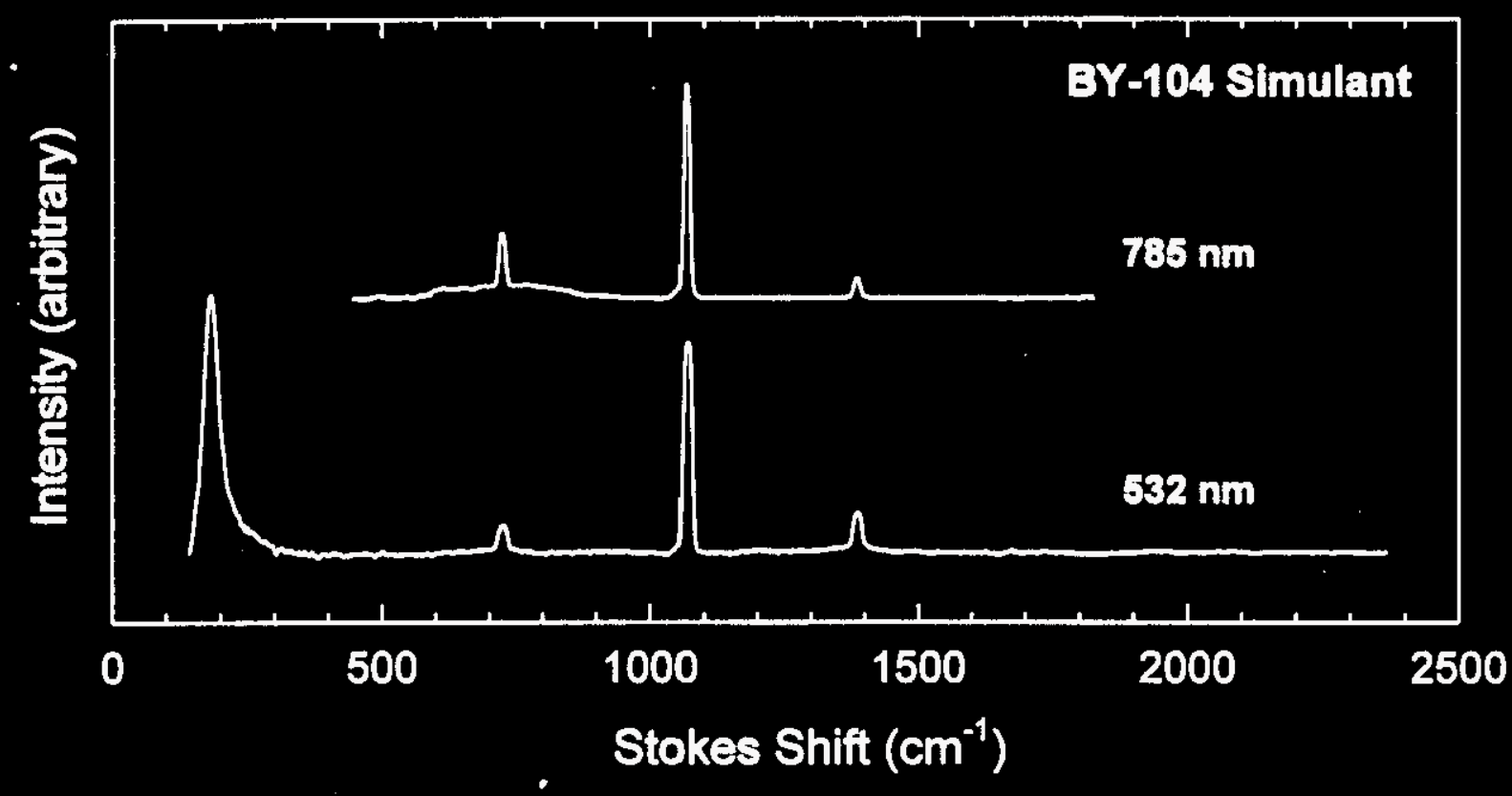

Figure C.6. In-Farm 2 Simulant Raman Spectra Using 532-nm and 785-nm Exeitation.

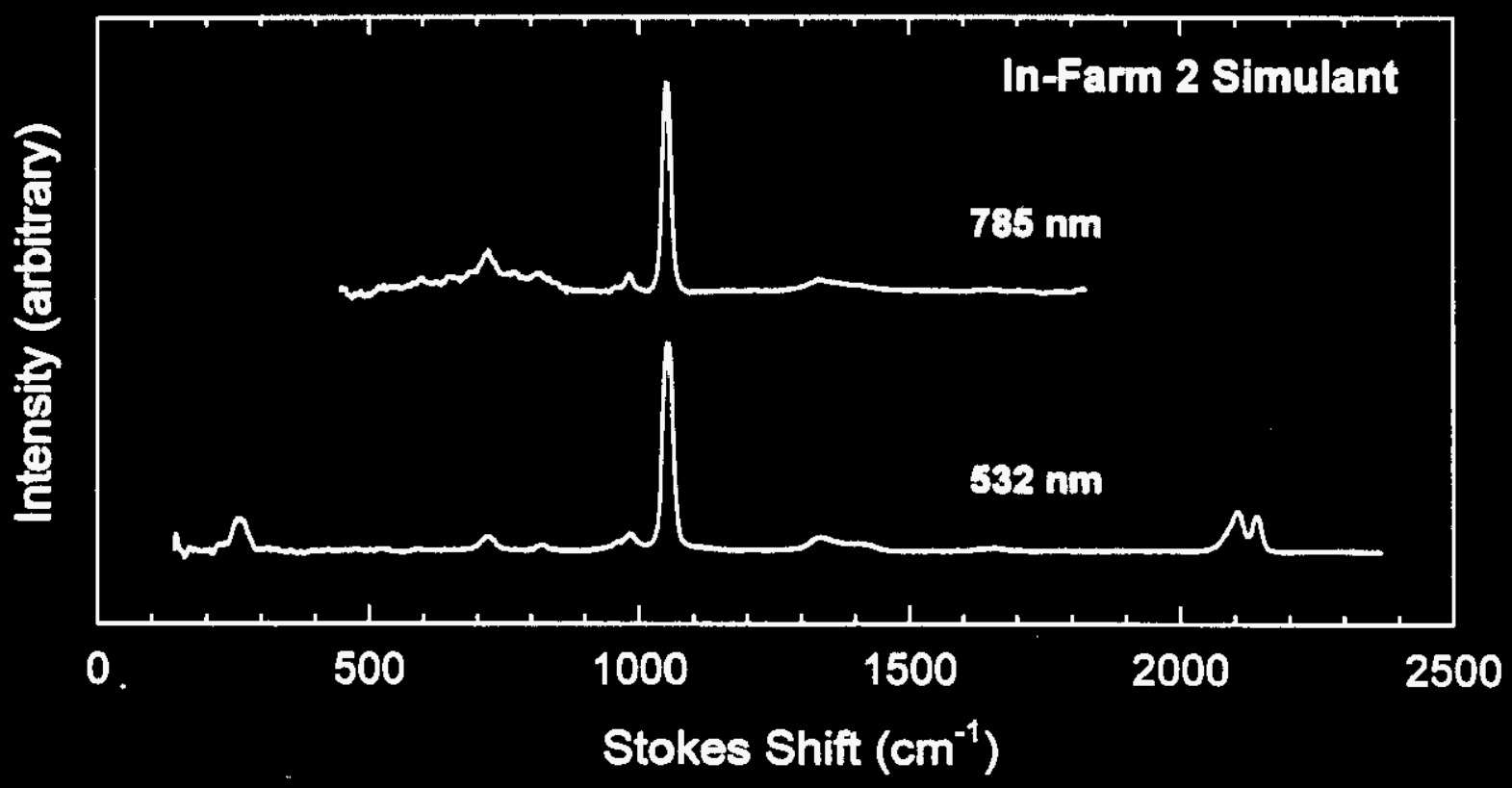


WHG-SB-TD-T1-003, Rov. 0

Figure C.7. SY-101 Simulant Raman Spectra Using 532-nm and 785-nm Excitation.

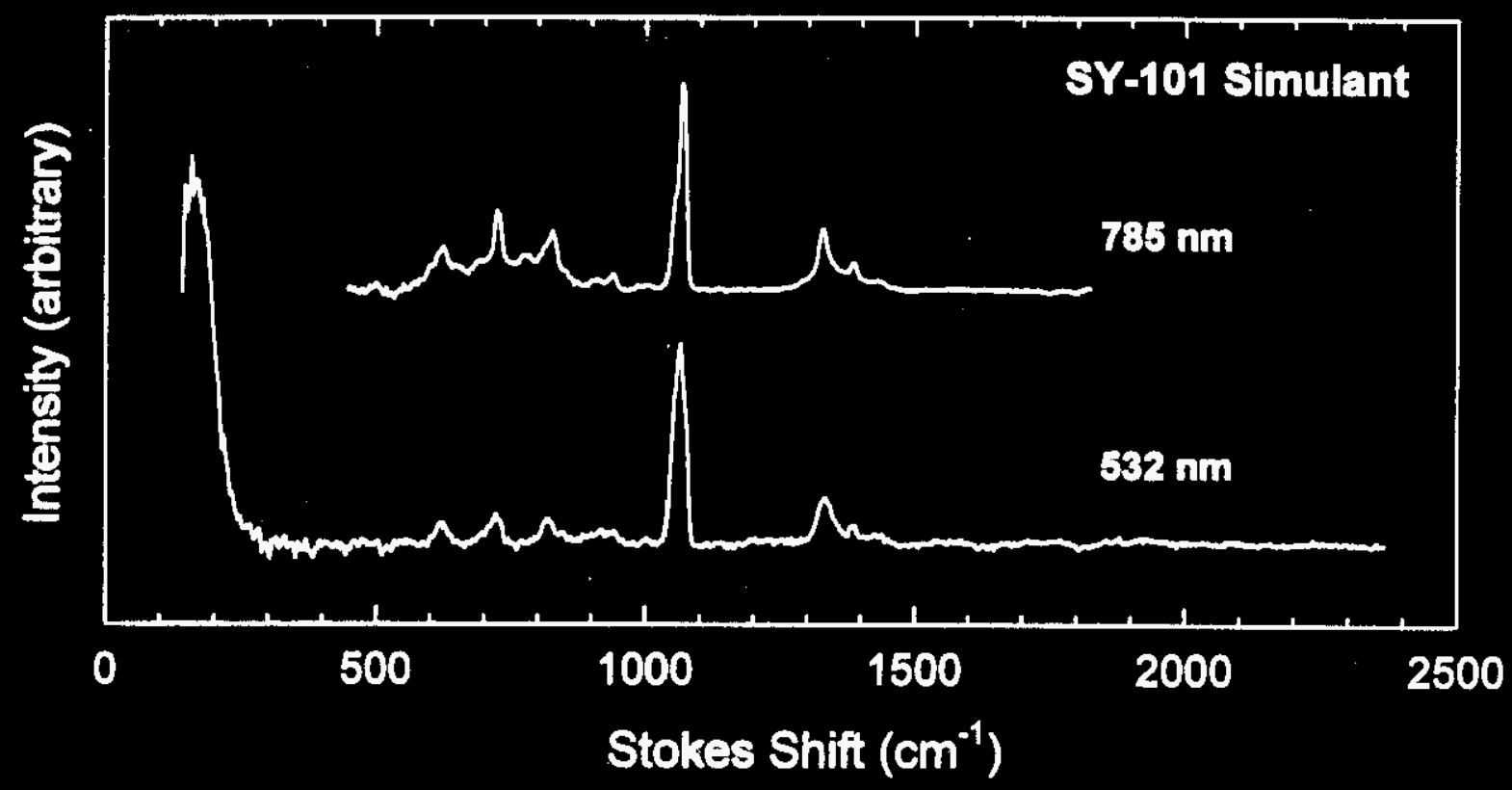

Figure C.8. T-Plant (Bottom Fraction) Simulant Raman Spectra Using 532-nm and 785-nm Ereitation.

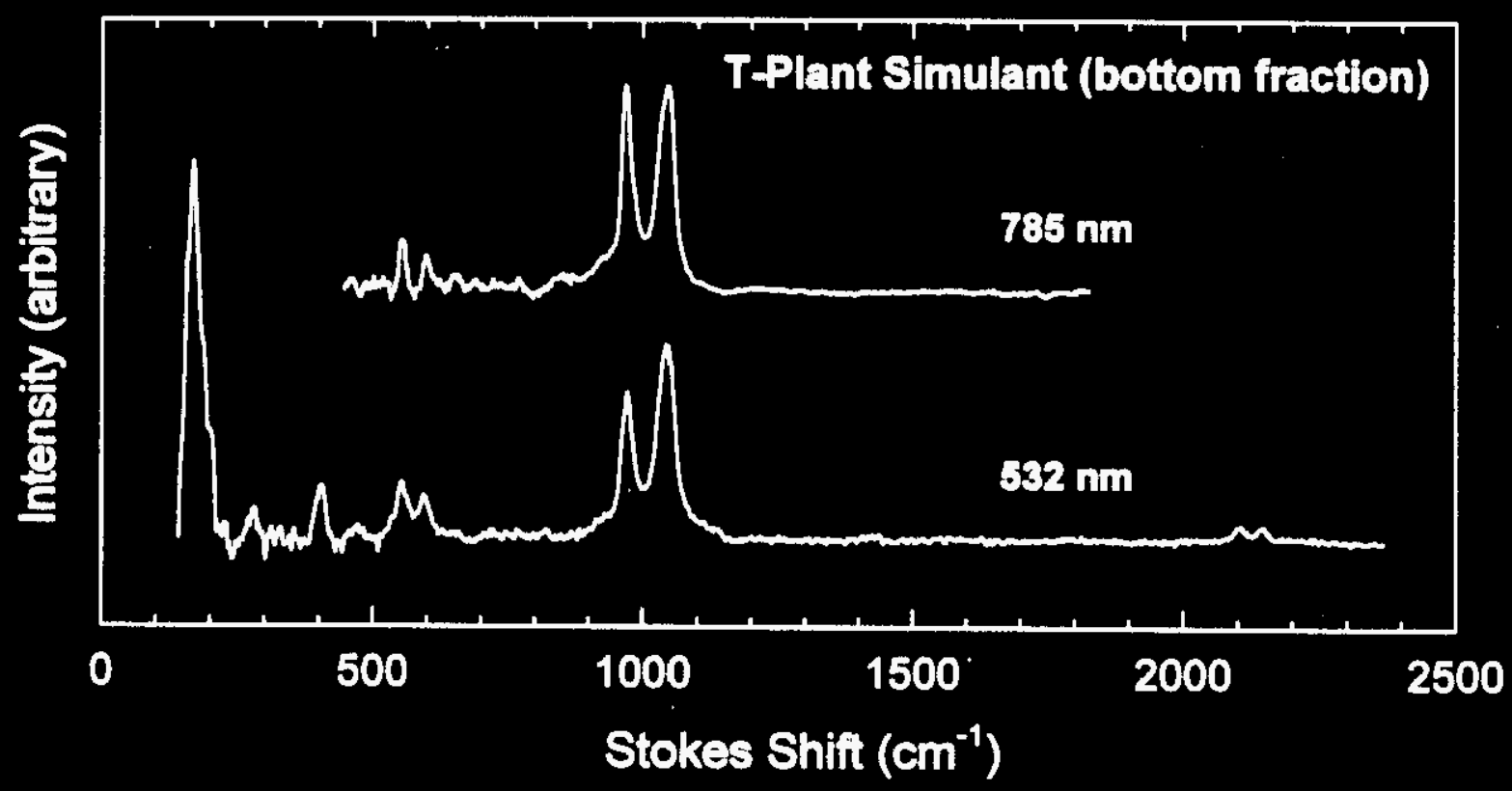

C-5 
Figure C.9. T-Plant (Top Fraction) Simulant Raman Spectra Using 532-nm and 785-nm Ereitation.

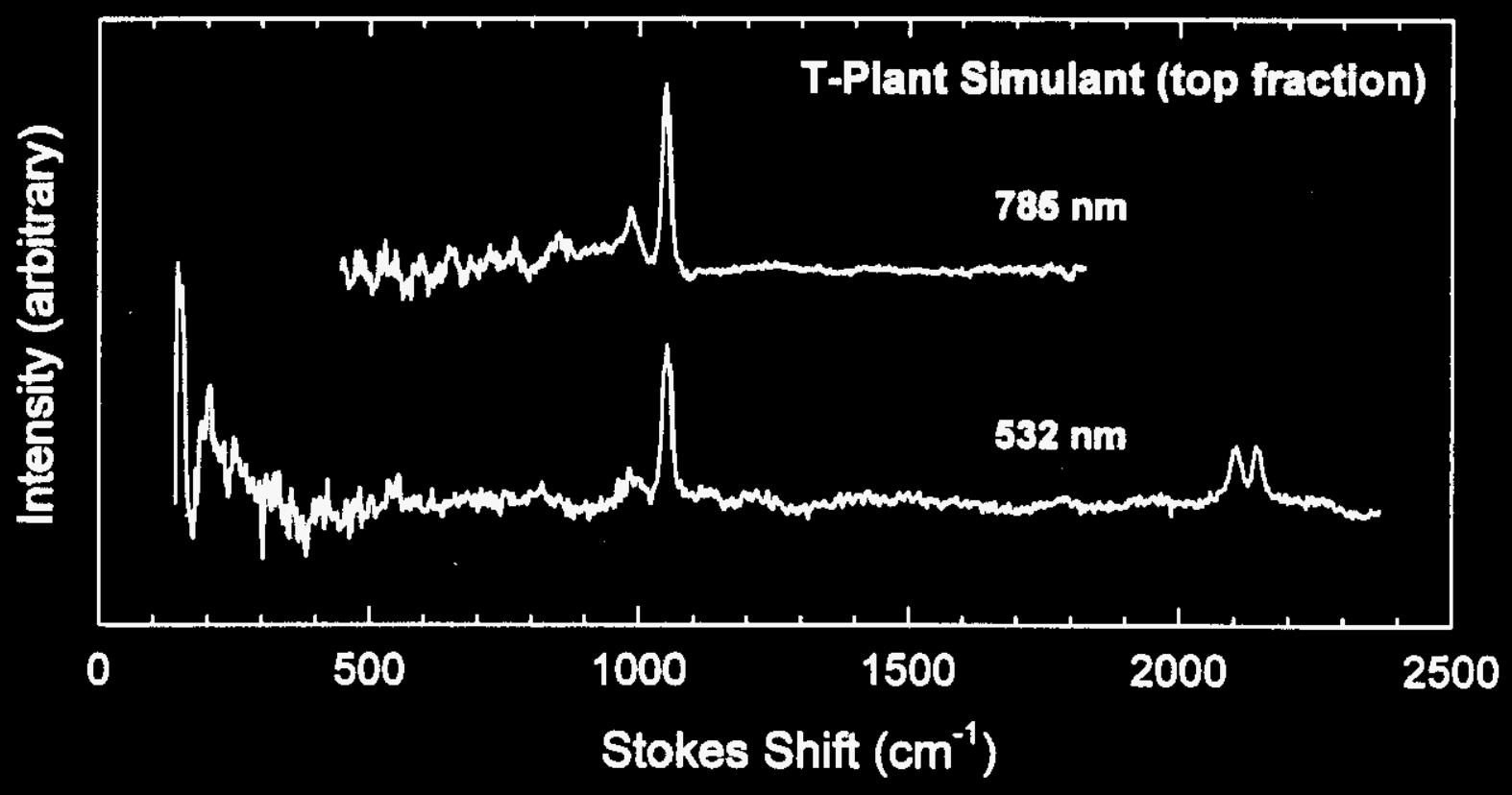


WHC-SD-TD-TI-003, Rov. 0

This page intentionally blank 
WHC-SD-TD-TI-003, Rov. 0

This page intentionally blank

C-8 


\section{DISTRIBUTION}

Number of Copies

\section{OFESITE}

IJ.S. Department of Eneroy. Headouaters 12800 Middlebrook Road

Germantown, Maryland 20874

R. Geiser

X. Lange

C. Purdy

S. Wolfe

1

IJ.S. Departinent of Eneroy. Moronntown Eneroy Technology Center

P.O. Box 880

3610 Collins Ferry Road

Morgantown, West Virginia 26507-0880

D. Mollot

1

U.S. Department of Enerry. Sayannah River Orapetions Office

P.O. Box A

Aiken, South Carolina 29808

T. Temple

1

IJ.S. Deportment of Enerry.

Science Amolications Intemational Compration

12850 Middlebrook Road

Trevion I, Suite 300

Germantown, Maryland 20874

R. Daniels 
Blante 


\section{DISTRIBUTION (cont)}

\section{Number of Copies}

\section{OFESTITE}

6

Tank Advisory Panel Members

C. S. Abrams

1987 Virginia

Idaho Falls, Idaho 83404

D. O. Campbell

102 Windham Road

Oak Ridge, Tennessee 37830

F. N. Carlson

6965 North 5th West

Idaho Falls, Idaho 83401

D. T. Oakley

409 12th Street SW, Suite 310

Washington, D.C. 20024-2188

W. R. Prindle

1556 Crestline Drive

Santa Barbara, Califomia 93105

A. Schneider

5005 Hidden Branches Drive

Dunwoody, Georgia 30338

Ames Labontory

Room 106, Spedding Hall

Iowa State University

Ames, Iowa 50011-3058

P. Wang 
Blank 
WHC-SD-TD-TL-003, Rev. 0

\section{DISTRIBUTION (cont)}

Number of Copies

OFESITE

1

Brookhayen National Laboratory

Upton, New York 11973

K. Bandyopadhyay

1

Eauske and Ascomiates, Inc.

16W070 W. 83rd Street

Burr Ridge, Illinois 60521

H. Fauske

2

Elorida State University

Department of Chemistry

Tallahasee, Florida 32306-3006

C. K. Mann

T. J. Vickers

1

Haryard University

295 Upland Avenue

Newton Highlands, Massachusetts 02161

M. First

Kaiser Ontical Syrstems, Inc.

P.O. Box 983

Ann Arbor, Michigan 48106

H. Owen 
blank 


\section{DISTRIBUTION (cont.)}

Number of Copies

OEFSITE

2

1

5

3
Lawnence Livemore National Laboratory

P.O. Box 808

Livermore, California 94550

B. Hudson

K. Kyle

Lockheed Idaho Technologies Co. P.O. Box 1625 ,

Idaho Falls, ID 83415

T. Thomas

MS 3423

Los Alamos Nitional Laliontory

P.O. Box 1663

Los Alamos, New Mexico 87545

S. Agnew

R. J. Donohoe

NC-14, MS C345

S. W. Eisenhawer

T. Larson

L. H. Sullivan

DX-DO, MS P915

Oak Ridre National Laboratory

P.O. Box 2008

Oak Ridge, Tennessee 37831

E. Collins

C. Forsberg

7930, MS-6385

T. Kress

MS-6495

9108, MS-8088 
Blank 


\section{DISTRIBUTION (cont)}

Number of Copies

OFFSTTE

1

Rice Inivensity

5211 Paisley

Houston, Texas 77096

A. Veletsos

2

Sandia National Laboratory

P.O. Box 5800

Albuquerque, New Mexico 87815

D. Powers

S. Slezak

6404, MS-0744

6415, MS-0741

Inivessity of Jdaho

Chemistry Department

Moscow, Idaho 83844-2343

P. Griffiths

1

University of South Carolina

Department of Chemistry/Biochemistry

Columbia, South Carolina 29208

\section{Angel}

University of Washington

Department of Chemistry, BG-10

131 Chemistry Library Bldg.

Seattle, Washington 98195

B. R. Kowalski 
Blank 


\section{DISTRIBUTION (cont.)}

\section{Number of Copies}

OFESITE

1

Vanderbilt University

P.O. Box 1596, Station B

Nashville, Tennessee 37235

F. Parker

1

Westinghouse, Sayemnah River Laboretory

P.0. Box 616

Aiken, South Carolina 29802

P. O'Rourke

\section{ONSITE}

U,S. Denogrtment of Eneroy. Bichland Fieldoffice

D. A. Brown

K8-50

R. F. Christensen

$\mathrm{K} 8-50$

J. M. Clark

S7-54

R. G. Harwood

57-54

P. R. Hemandez

57-54

W. F. Hendrickson

57-54

T. Noble

S7-54

1

Los.Alamos National Laboratory

P. G. Eller

57-53

1

Mactech .

V. FitzPatrick

K8-50 
Blank 


\section{DISTRIBUTION (cont.)}

\section{Number of Copies}

\section{ONSITE}

7

\section{Pacific.Northwest Laboratory}

S. A. Bryan

D. M. Camaioni

S. D. Colson

J. S. Hartman

A. F. Noonan

R. D. Scheele

M. J. Quadrel

40
P7-25

K2-44

K2-14

K5-25

K9-91

P7-25

K9-69

\section{Westinghouse Hanford Company}

R. Akita

T6-20

H. Babad

S7-15

J. D. Berger

L0-18

D. C. Board

S7-07

G. N. Boechler

H5-09

D. R. Bratzel

S7-21

R. J. Cash

S7-15

B. A. Crawford

T6-09

D. A. Dodd

T6-50

J. G. Douglas

L5-55

G. T. Dukelow

S7-15

J. B. Duncan

L5-55

S. J. Eberlein

R2-12

J. C. Fulton

R3-11

V. W. Hall

T6-04

C. E. Hanson

H5-09

M. N. Islam

R3-08

D. W. Jeppson

L5-31

J. R. Jewett

T6-09 
- Blank 
WHC-SD-TD-TI-003, Rov. 0

DISTRIBUTION (cont)

Number of Conies

ONSITE Westinghouse Hanford Comnany (cont.)

T. J. Kelley

S7-21

L. L. Lockrem

S3-90

T. Lopez

L5-55

J. E. Meacham

S7-15

S. J. Mech

L5-55

C. T. Narquis

T6-16

M. A. Payne

S7-84

T. V. Rebagay

T6-30

F. R. Reich

L5-55

D. A. Reynolds

R2-11

D. A. Turner

S7-15

W. T. Watson

H0-38

W. D. Winkelman

L5-55

P. A. Young

S7-16

W. F. Zuroff

R1-49

Central Files (original +2 )

A3-88

EDMC

H6-08

ext?

$E=4$

Tank Farm Information Center

R1-20 


\section{Blank}

